\title{
A systematic review of objective burn scar measurements
}

Kwang Chear Lee ${ }^{1,4^{*}}$, Janine Dretzke ${ }^{2}$, Liam Grover ${ }^{3}$, Ann Logan $^{4}$ and Naiem Moiemen ${ }^{1}$

\begin{abstract}
Background: Problematic scarring remains a challenging aspect to address in the treatment of burns and can significantly affect the quality of life of the burn survivor. At present, there are few treatments available in the clinic to control adverse scarring, but experimental pharmacological anti-scarring strategies are now beginning to emerge. Their comparative success must be based on objective measurements of scarring, yet currently the clinical assessment of scars is not carried out systematically and is mostly based on subjective review of patients. However, several techniques and devices are being introduced that allow objective analysis of the burn scar. The aim of this article is to evaluate various objective measurement tools currently available and recommend a useful panel that is suitable for use in clinical trials of anti-scarring therapies.

Methods: A systematic literature search was done using the Web of Science, PubMed and Cochrane databases. The identified devices were then classified and grouped according to the parameters they measured.

The tools were then compared and assessed in terms of inter- and intra-rater reproducibility, ease of use and cost.

Results: After duplicates were removed, 5062 articles were obtained in the search. After further screening, 157 articles which utilised objective burn scar measurement systems or tools were obtained. The scar measurement devices can be broadly classified into those measuring colour, metric variables, texture, biomechanical properties and pathophysiological disturbances.

Conclusions: Objective scar measurement tools allow the accurate and reproducible evaluation of scars, which is important for both clinical and scientific use. However, studies to evaluate their relative performance and merits of these tools are scarce, and there remain factors, such as itch and pain, which cannot be measured objectively. On reviewing the available evidence, a panel of devices for objective scar measurement is recommended consisting of the 3D cameras (Eykona/LifevizNectra H1) for surface area and volume, DSM II colorimeter for colour, Dermascan high-frequency ultrasound for scar thickness and Cutometer for skin elasticity and pliability.
\end{abstract}

Keywords: Scar measurement, Burn, Objective measurement, 3D camera, Laser imaging, High-frequency ultrasound image, Colorimeter, Cutometer

\section{Background}

Burn injury is one of the most common type of traumatic injuries in the world with an estimated incidence of 1.1 per 100,000 population [1] and remains one of the leading causes of deaths, accounting for $5.2 \%$ of 5.1 million deaths due to injuries and violence in 2012 [2]. In the last few decades, major advances in burn care have greatly improved survival rates [3] and an increased number of patients are surviving

\footnotetext{
* Correspondence: kwangchear@hotmail.com

Ann Logan and Naiem Moiemen are joint last authors.

${ }^{1}$ The Healing Foundation Burn Research Centre, University Hospital

Birmingham Foundation Trust, Birmingham B15 2TH, UK

${ }^{4}$ School of Clinical and Experimental Medicine, College of Medical and Dental Sciences, University of Birmingham, Birmingham B15 2TT, UK Full list of author information is available at the end of the article
}

large burns. Non-fatal burns however is a leading cause of morbidity, as many of these patients develop hypertrophic scars that may lead to significant disfigurement and disability (e.g. contractures).

In order to assess and track the evolution of scars over time, subjective rating scales have been introduced into clinical practice. These scales in general are free or low cost and require minimal training to utilise. Several such scar scales have been developed and are used widely, including the commonly used Vancouver Scar Scale (VSS) and the Patient and Observer Scar Assessment Scale (POSAS) [4]. However, these scar scales are considered to be subjective and the resulting scores can vary between different assessors (inter-assessor variation) [5], different scar severities [6] and age of the scar [7], and some studies have suggested 
that more than one rater (sometimes as many as five), and utilising the average, is required in order to produce reliable ratings $[7,8]$. The POSAS attempts to improve the method of rating scars by including the patients' perspective; however, patients' perception and subjective evaluation of their scars have been shown to be influenced by depressive symptoms [9]. The physical characteristics of scars further add to the complexity of rating as changes in both the vascularity and pigmentation can occur simultaneously, and scars are also rarely homogenous in both colour and texture, which makes estimation of mean values difficult and inaccurate for a human observer.

Standardised, quantifiable, reliable (reproducible) and valid assessment tools that provide a more objective evaluation of scars are essential for monitoring the changes in scar quality over time and also to determine the effectiveness of scar treatments.

The various objective measures that relate to scar severity can be divided into the following categories:

- Colour: erythema and pigmentation contribute significantly to the appearance of a scar.

- Dimensions: it includes planimetry (surface area), thickness and volume.

- Texture: surface texture or scar roughness has a significant effect on the patient's and observer's opinion of the scar.

- Biomechanical properties: it includes pliability and elasticity. Stiffness and hardening of scars are due to increased collagen synthesis and lack of elastin in the dermal layer and can lead to impairment of skin function, especially when the scar is located around joints.

- Pathophysiological disturbances: it includes transcutaneous oxygen tension and transepidermal water loss and moisture content.

- Tissue microstructure: new non-invasive in vivo imaging techniques analyse the morphological tissue architecture of the scar, providing measurements previously only possible by histopathological analysis of biopsy samples.

- Pain/sensation: pain is a commonly measured parameter in many subjective scales however objective methods to measure it are yet to be available. However the measurement of altered sensation may be useful.

In this article, we describe and compare the underlying principles and performance of various currently available objective measurement devices in order to inform clinicians and researchers about their clinical utility for scar assessment. In addition, we discuss innovative technologies that may be applicable to burn scar assessment in the near future.

\section{Methods}

\section{Criteria for considering articles for inclusion}

Published articles that describe non-invasive burn scar measurements were included in this systematic review. Studies that used scar scales which utilise subjective scoring systems were excluded, as studies that made histopathological evaluations of scars via biopsies had no potential to be used in vivo (i.e. requiring the use of ex vivo processing and staining). We chose to include studies comparing the outcomes of wound or scar treatments as well as animal studies and in some cases non-burn scars if appropriate, as excluding these studies may prevent us from identifying new or emerging technologies.

\section{Search methods}

A computerised literature search (until October 2015) was performed using the web-based Web of Science (http://wok.mimas.ac.uk/; years 1900-2015) and PubMed services (www.ncbi.nlm.nih.gov/pubmed/; years 19502015) and utilising the Web of Science Core collection and Medline databases. No language limit was set.

The following search strategies were used:

1) (Skin OR derma* OR dermis OR epidermis OR epiderma*) AND (scar OR cicatrix OR fibrosis) AND (objective OR quantitative) AND (burn OR burn\$ OR hypertrophic).

2) (Skin OR derma* OR dermis OR epidermis OR epiderma*) AND (scar OR cicatrix OR fibrosis) AND (evaluation OR assessment) AND scale

3) ((burn\$ or burn) and hypertrophy)

4) ((burn\$ or burn) and (scar or cicatrix))

5) ((scar or cicatrix or fibrosis) and hypertrophy)

6) ((Objective assess* or objective evaluat* or objective measure* or assess $\$$ instrument or assess \$ tool or device or measurement system or objective) adj3 assess\$)

7) (objective evaluat* or objective measur* or assess\$ instrument or assess\$ tool or (device or scale or measurement system))

8) NOT (uterus or cardio* or neoplasm or cancer or metastas\$ or malignancy)

Web of Science core collection results were further refined by the following terms: surgery or dermatology or critical care medicine or emergency medicine or medicine research experimental or computer science interdisciplinary applications or computer science artificial intelligence or imaging science photographic technology or rehabilitation or medical laboratory technology or engineering biomedical or medicine legal or medical informatics or biophysics or anatomy morphology. 
This search produced 5062 articles after duplicates $(n=2334)$ were removed. After filtering by review of titles and abstracts, 151 suitable articles were chosen.

A separate search was also conducted using the PubMed database (www.ncbi.nlm.nih.gov/pubmed) using the following keywords/terms (including MeSH [Medical Subject Headings] terms): skin AND (scar OR cicatrix OR fibrosis) AND (evaluation OR assessment OR assess OR measure OR measurement) AND (objective OR quantitative) AND (burn OR burns OR hypertrophic). A further broader search was conducted using the following keywords and MeSH terms: skin AND (scar OR cicatrix OR fibrosis) AND (evaluation OR assessment) AND scale. No language limit was set. This search retrieved 613 articles, and after filtering by review of titles and abstracts and removal of duplicates, a further 27 articles were included. The reference lists of the selected articles were also searched for suitable studies, and an additional 12 articles were included.

A search of the Cochrane database retrieved no suitable articles.

A grey literature search was performed using the Bielefeld Academic Search Engine (BASE) database with the term "objective measurement of scarring". This search included books, reports, papers, lectures, theses, reviews, and primary data document types and excluded article, journals, audio, videos, images, maps, software and sheet music document types. This search produced 180 hits (after 50 duplicates removed), and after review, 6 articles were deemed suitable for inclusion into the review.

Full text articles were obtained for the articles where possible, and a further 28 records were removed after evaluating the full text. Articles which were only available in abstract form and had no extractable data were also excluded.

Thus, the total number of articles selected for review was 157. This includes 9 review articles.

The selection process for the eligible articles is outlined in Fig. 1 below.

\section{Quality assessment}

The validity and reproducibility of the devices were evaluated when statistical data were available especially in terms of reproducibility of the assessments. Where available, the additional value of the device compared with subjective scar scales and/or other tools is discussed.

In terms of interpreting the intra-class correlation coefficients (ICC), some guidelines have been provided by Landis and Koch [10] for Kappa coefficients (which are also reasonable for the ICC) suggesting that:

- Kappa of <0.00 indicates "poor" agreement

- Kappas from 0.00 to 0.20 indicate "slight" agreement

- Kappas from 0.21 to 0.40 indicate "fair" agreement

- Kappas from 0.41 to 0.60 indicate "moderate" agreement

- Kappas from 0.61 to 0.80 indicate "substantial" agreement

- Kappas from 0.81 to 1.00 indicate "almost prefect" agreement

However, it should be noted that these guidelines are subjective.

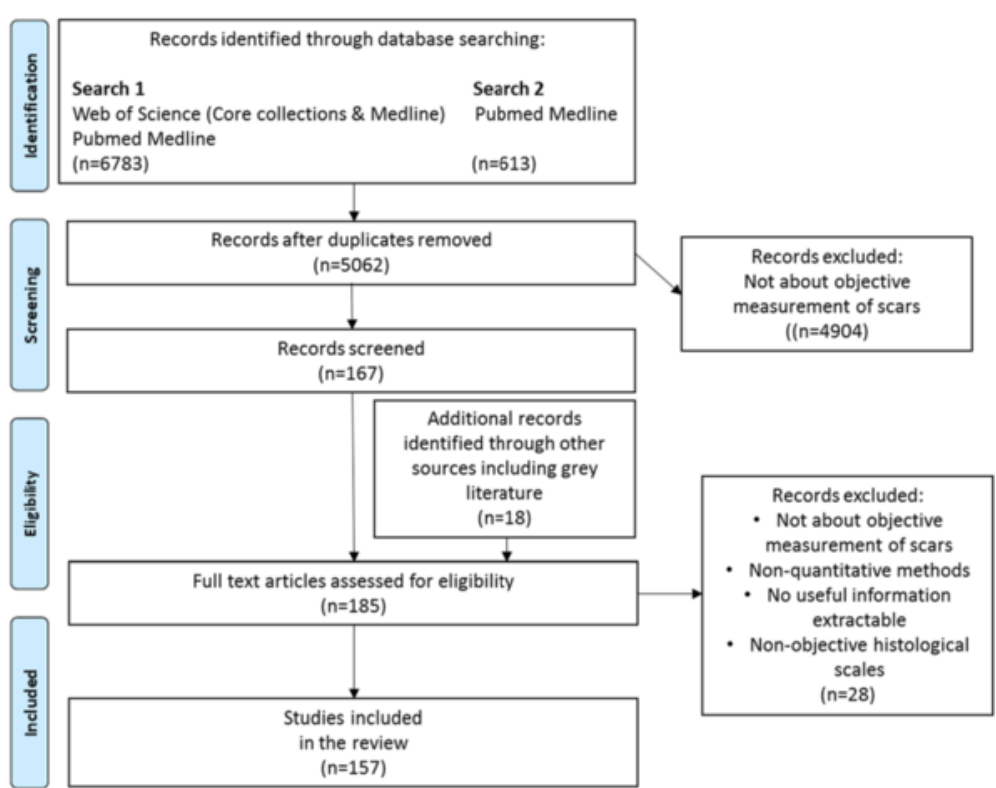

Fig. 1 Preferred Reporting Items for Systematic Reviews and Meta-Analyses flowchart 
Feasibility of devices was assessed via the commercial availability, portability and cost of the devices.

An economical assessment of the devices based on the literature was not possible due to the lack of such data in the articles; however, several of the companies with commercially available devices were contacted to provide quotes, and although it was not possible to publish the exact prices due to confidentiality issues, the devices are categorised into price ranges $(<£ 5000$, $£ 5000-10,000,>£ 10,000,>£ 30,000)$.

\section{Results}

Articles, reviews and editorials that described objective burn scar assessments were retained. These were then classified into six categories based on the assessed variables: (1) colour, (2) scar dimensions (e.g. thickness or height, surface area), (3) texture, (4) biomechanical properties (e.g. elasticity, pliability), (5) physiological disturbances (e.g. hydration) and (6) non-invasive morphological imaging techniques.

\section{Colour}

Colour is a major factor that affects the aesthetics of a scar and is mainly composed of two components: melanin (the brown pigment made by activated cutaneous melanocytes) and erythema (the redness that is caused by haemoglobin in the dilated/congested remodelled cutaneous vasculature). Other pigments that localise in scars, such as bile and carotene, may also contribute to the overall appearance of the scar. Colour measurements can be used to gauge the effectiveness of anti-scarring treatments since they reflect abnormal skin architecture/composition [11]. Measurement of the scar colour can be complicated by several factors, such as skin layer thickness, reflection from the skin surface and environmental factors including light and temperature. The measurement of erythema is further influenced by patientrelated factors such as activity and positioning of affected areas as such movements may affect the blood circulation and hence the erythema of the skin.

Although visual assessment of colour has been incorporated into various scar scales, it is a subjective evaluation method that provides relative rating systems. Even in normal circumstances, the human brain cannot accurately quantify colour or its intensity. A famous recent example of this is the "blue and black dress" which shows that human colour discrimination may be affected by the illuminant colours, level of ambient illumination and the background colours of a visual display terminal $[12,13]$. Neuropsychiatric conditions have also been shown to affect colour discrimination [14]. In scars, changes in vascularity and pigmentation occur simultaneously and overlap each other which make colour observation and reporting even more difficult for a human observer, e.g. it is difficult to assess the pigmentation of a scar in a highly vascularised scar as the erythema would obscure the increase or lack of pigment. Additionally, as scars often have an uneven colour distribution, human observers cannot easily or accurately provide a mean value for a certain area.

More recently, several objective and reproducible methods of colour evaluation have been developed and they can be broadly classified as follows:

- Reflectance spectroscopy: tristimulus reflectance colorimetry and narrow-band spectrophotometry

- Laser imaging: it measures the microcirculation in the scar which influences the erythema of the scar.

- Computerised analysis of digital photographs: it can include two-dimensional (2D) and threedimensional (3D) images which are then digitally analysed to quantify colour values.

\section{Reflectance spectroscopy}

Reflectance spectroscopy is a well-established technique of more than 50 years [7] and currently one of the most commonly used methods for measuring colour. Techniques that utilise reflectance spectroscopy quantitatively measure the colour and intensity of reflected light. For example in Fig. 2, when light consisting of red, blue and green is shone upon a surface, if the material absorbs red and green light, then only the blue light is reflected which will make us perceive the material as blue. A biological example is the detection of the oxygenation of haemoglobin. When haemoglobin is illuminated with white light, oxygenated haemoglobin will absorb a higher proportion of blue light and reflect back red light whereas de-oxygenated haemoglobin absorbs more red light and thus appears bluer. In reality, the process is more complicated as the light that is shone (termed incident light) onto biological tissues can be reflected in many different trajectories, and this scattering also influences our perception of the colour of an object.

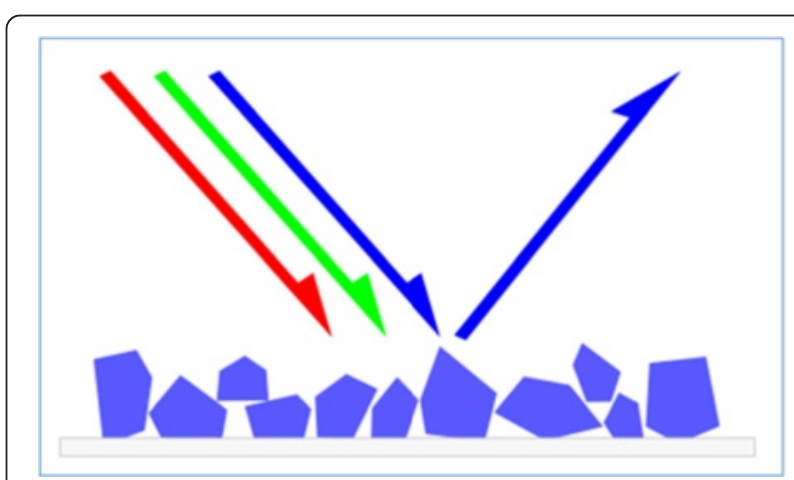

Fig. 2 Graphical illustration of the concept of reflectance spectroscopy. (Source: http://commons.wikimedia.org/wiki/ File:Simple_reflectance.svg) 
Tristimulus reflectance colorimetry and narrow-band simple reflectance (or spectrophotometry) are both based on the principle of reflectance spectroscopy.

Tristimulus reflectance colorimetry [15] describes colour by three values: $L^{*}$ (clarity, lightness or brightness); $a^{*}$, the amount of red or green (erythema); and b*, the amount of yellow or blue (pigmentation) (see Fig. 3). For example, a white coloured object would have a higher L* value compared to a darker coloured object and a scar that it is redder than normal skin would give a higher $\mathrm{a}^{*}$ value than normal skin. Additionally, another approach to quantify colour is by using the saturation or chroma of colour $(C *)$ which is a vector magnitude in the chromatic plane calculated from $\mathrm{a}^{*}$ and $\mathrm{b}^{*}$ values $[16,17]$.

There are currently several spectrocolorimeter devices that utilise the principle of tristimulus reflectance colorimetry, including the Minolta Chromameter [15, 18, 19] (Minolta Camera Co., Osaka, Japan), the Labscan XE [17] (Hunter Associates Laboratory, Inc., Reston, VA), DSM II Colormeter [20], NF-333 [21] (Nippon Denshoku Co. Ltd, Japan), Micro Color (Dr. Bruno Lange GmBH, Dusseldorf, Germany) [22], X-Rite SP64 Spectrophotometer (X-rite Inc, Michigan, USA) [23] and the Visi-Chroma VC-100 (Biophotonics, Belgium) [22, 24]. Camera systems such as the Eykona 3D camera can also be calibrated to report colour values using the L"a*b* system [25]. However, a drawback of the Eykona 3D camera is that although its cost is low, it currently requires consumables in the form of one-use targets (about $£ 70$ for 25 targets) that have to be placed next to the area of interest when taking an image, although there are plans to introduce reusable targets in the coming months according to the company.

A study by Li-Tsang et al. [17] showed that the intraand inter-rater reliability for the Labscan XE device for

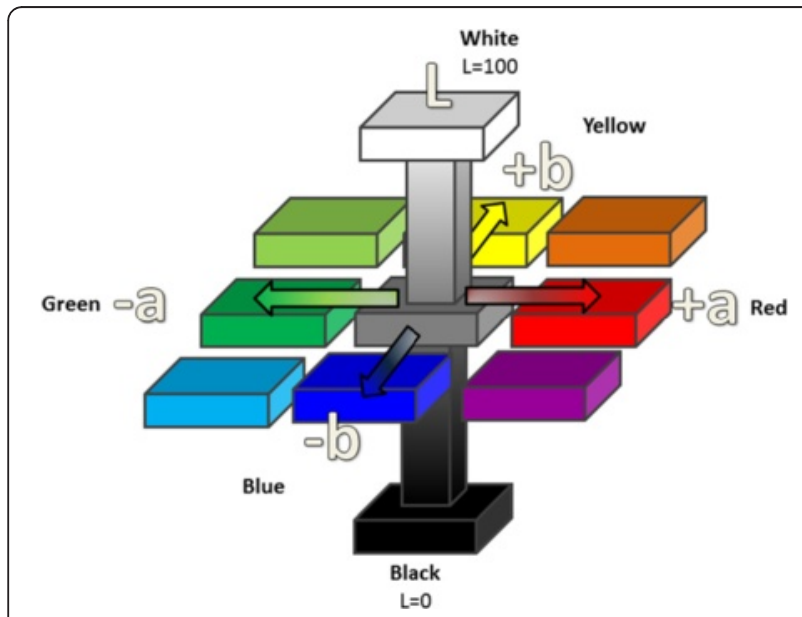

Fig. 3 Graphical representation of the $L^{*} a^{*} b^{*}$ colour measurement system. (Source: Kwang Chear Lee) hypertrophic scars was satisfactory, with an intra-class correlation coefficient (ICC) ranging from 0.95 to 0.99 for intra-rater reliability, and 0.50 to 0.99 for inter-rater reliability in all the three colour parameters ( $\mathrm{L}^{*}, \mathrm{a}^{*}$ and $\left.\mathrm{b}^{*}\right)$. A strong positive correlation was also found between VSS scores and the readings obtained from the Labscan XE device. The device that was utilised in the literature was not portable; however, newer portable versions are currently available. A study by Draaijers et al. showed that the overall evaluations of scar colour with both the Dermaspectrometer and the Minolta Chromameter are more reliable than the visual evaluation and scoring of scar colour carried out by observers using a 10-step score, whereby a score of 1 reflects normal skin and a score of 10 reflects the worst scar imaginable [15]. However, devices that rely solely on tristimulus colorimetery have been shown to have poor correlation scores with patient scar scales when measuring pigmented or hypo-pigmented scars due to the scar scales scoring hyper- and hypo-pigmented scars higher as deviations from normal skin.

Narrow-band spectrophotometry [15] devices on the other hand measures the vascularisation and pigmentation of the scar based on differences in red and green light absorption by haemoglobin and melanin, respectively. The Dermatospectrometer (or the newer version, DSM II Colormeter) [20, 26, 27] (Cortex Technology, Hadsund, Denmark) and Mexameter [20, 28] (Courage + Khazaka, Germany) are examples of a device that uses this principle. In comparison with the Minolta Chromameter and Labscan XE, the Dermaspectrometer is a smaller and hence a more portable device and the use of the erythema and melanin indexes is less complicated to understand and analyse compared to the $\mathrm{L}^{*}$, $\mathrm{a}^{*}$ and $\mathrm{b}^{*}$ of the Minolta Chromameter. It has also been shown to have a slightly better correlation with clinical scores when compared with the Chromameter [29]. Unfortunately, the Dermatospectrometer has been withdrawn from the market but it has been replaced with a newer model, the DSM II Colormeter. The DSM II Colormeter [20] (Cortex Technology, Denmark) is a small, fully hand-held device that utilises both tristimulus colorimetry and narrow-band spectrophotometry technology and produces reliable readings [20]. It has an improved utility, in terms of cost and assessment time as it utilises one instrument instead of two to obtain both tristimulus colorimetry readings as well as narrow-band spectroscopy readings. The Mexameter also has good intra-observer and inter-observer reliability in scar assessments [20].

Caution however must be used when using erythema to grade the severity of scars. This is because scars can often be very vascular initially but this does not mean that they will become hypertrophic, e.g. in the study by Nedelec et al. [30], the Mexameter was unable to differentiate hypertrophic scars from normal scars as donor 
sites were very erythematous, but we know that donor sites rarely progress to become hypertrophic scars.

A common disadvantage of all of the aforementioned devices is that they employ a small measuring area, e.g. the measuring area for the Minolta Chromameter is only $3 \mathrm{~mm}$ [18] and the other devices range from 5 to $8 \mathrm{~mm}$ [7]. Therefore, multiple measurements, especially in larger scars, need to be performed to provide accurate scores, but these increase the risk of observational bias. Additionally, these devices also require contact with the skin which can change the colour if too much pressure is applied. Environmental lighting may also affect the readings obtained, although many of the companies of these devices (e.g. DSM II Colormeter) claim that the flash that is utilised by these devices is strong enough to overcome and compensate for any differences in colour caused by indoor lighting.

\section{Large area spectrophotometry}

Some investigators have attempted to overcome the problem of small measurement areas by utilising camera systems to allow the imaging of larger areas. Cheon et al. utilised digital photographs taken with a digital camera (Nikon D70s, Tokyo, Japan) under the same light source and obtained $L^{*} a^{*} b^{*}$ values for the regions of interest (whole scar lesions when possible) using Adobe Photoshop (Adobe systems Incorporated, San Jose, CA). The test-retest consistency (or intra-rater reliability) of the $\mathrm{L}^{*} \mathrm{a} \mathrm{b}^{*}$ as determined by the intra-class coefficient ranged from 0.95 to 0.99 and the inter-rater reliability was also good with values ranging from 0.94 to 0.98 [31, 32].

Another method of spectral modelling developed by Kaartinen et al. utilises standardised digital imaging (SDI) with computer controlled lighting to quantify colour changes $[7,8,33]$. This system allows a larger area of the skin to be analysed with an only slightly weaker accuracy compared to the previously mentioned spectroscopybased systems [33]. This method, however, is yet to become commercially available, but a similar system, Scanoskin (Leniomed Ltd, London, UK), is available. The Scanoskin system utilises polarised light, which has the advantage of blocking the reflectance from the skin which allows better analysis of the epidermal and superficial dermal layers [34]. The system is currently used only to assess burn depth via the imaging of haemoglobin (erythema/ vascularisation) and haemosiderin or melanin. Images which are taken (with a modified SLR camera with polarised lenses) are processed by the provided software which splits them into separate erythema and melanin components. Quantification of erythema and pigmentation (melanin) has to be performed on the exported images using software such as Image [35-37].

The evidence for using objective measures in measuring colour is encouraging and is based on a relatively small number of studies, and more research is needed [38].
Spectrophotometric intra-cutaneous analysis (SIA)

Analysis of colour information purely in the visible spectrum is insufficient to provide information relating to a lesion's deeper structures, and it was this realisation that prompted research at the University of Birmingham to extend the spectrum of light used into the infrared region (700-1000 nm). Spectrophotometric intra-cutaneous analysis via the clinical device, SIAscope, utilises a probe $(12 \times 12 \mathrm{~mm}$ or $24 \times 24 \mathrm{~mm})$ that utilises radiation ranging from 400-1000 $\mathrm{nm}$ and produces 8 narrow-band spectrally filtered images of the skin which are then processed by software algorithms and allows the visualisation and quantification of melanin, collagen and blood [39]. Although developed for diagnosing skin cancers, it can and has been used to monitor the changes in scar tissue in response to treatment [40].

\section{Computerised analysis of digital photographs}

Digital photographs can be taken with any standard digital camera, e.g. the Nikon 8400 [19].

Photos are then downloaded for analysis by proprietary software packages such as KS400 (Kontron Electronic GMB, Carl Zeiss Micro-Imaging, Inc., Thornwood, NY, USA) [41] or the freely available ImageJ. One study utilised an artificial neural network to perform chromatic analysis of the digital image of a burn scar [42]. Colour measurements using ImageJ have been shown to be equivalent to those obtained using a colorimeter (Chromameter, Konica-Minolta) [19]. Several studies have attempted to improve the objectivity of photograph analysis of scars by standardising factors such as distance and lighting [19] or using computerised image capturing systems [43-45]. However, even this method fails to allow scars to be compared objectively as humans vary in terms of how we set the measurement criteria for and analyse colour [29, 46] and the photographs have been shown to have limited utility when assessed using computer-based subjective scales [47]. Improved computer programmes may overcome the limitations of the human brain and provide objective analysis of the digital photographs. However, computer programmes cannot properly "see" colour and thus have to convert colour information into digital data, thereby losing valuable information.

Computer programmes utilise two methods to analyse colour. The hue-saturation-value (HSV) method analyses colour by separating it into three main components: hue (dominant wavelength), saturation (amount of white) and value (amount of black). The other method utilises colour models of which there are two main ones: the Red, Green and Blue (RGB) model and the Cyan, Magenta, Yellow and Black (CMYK) model. Measurement techniques using other systems such as the $\mathrm{L}^{*} \mathrm{a}^{*} \mathrm{~b}^{*}$ system have also been described [48]. 
To remove the influence of light and camera settings, generally a card carrying standard colours (e.g. Pantone colour chart [Pantone Inc, USA] [16], Macbeth Digital Colorchecker SG colour chart [Munsell Colour services Laboratory, X-Rite Inc, Michigan, USA] [25, 44]) is recommended to be placed beside the scar being photographed so that every photo taken would include areas of known colour properties, allowing an objective colour evaluation [16].

Table 1 summarises the colour measurement devices in terms of parameter measured, reliability, correlation with clinical score and cost.

\section{Laser imaging}

The amount of haemoglobin or erythema present in a scar can be measured indirectly via laser imaging $[49,50]$ that measures the blood flow in a scar. Immature scars show a significantly increased blood flow due to their higher vascularity compared to mature scars. Increased microcirculatory blood flow (as measured by Laser Doppler Flowmetry (LDF)) has also been shown to be a potential indicator for the occurrence of hypertrophic scarring [51]. Hypertrophic scars will typically generate readings that are two to three times greater than that made in normal skin $[50,52,53]$ and four times greater than that in a non-hypertrophic scar [50]. Laser-based methods have the advantage of being fast, reproducible and having a good correlation with the VSS; however, they are subject to structural changes in the skin and environmental and body temperature fluctuations [54-56].

Laser-based methods can be divided into three techniques: LDF, Laser Doppler Imaging (LDI) and Laser Speckle Imaging (LSI)/Laser Speckle Perfusion Imaging (LSPI). With the older Laser Doppler Flowmeter, the fibre optic probe is in contact with the tissue surface and is a single-point measure [49, 57]. Laser Doppler Flowmeter [29, 52, 55, 56] systems, such as the DRT4 [53] (Moor instruments, Devon, UK) or the LaserfloBPM [58] (Vasamedics Corp, St Paul, Minnesota, USA), the fibre optic probe is in contact with the tissue surface and provides a single-point measure of an indirect evaluation of scar colour by measuring the cutaneous bloodflow present in a scar $[49,57]$. LDF systems are more limited compared to the other laser-based methods (see below) as they measure flow within a small area and, thus, are unsuitable for use with larger, heterogeneous scars.

In contrast, Laser Doppler Imaging (LDI) devices, such as the Lisca PIM1.0 imager (Lisca Development AB, Linköpen, Sweden) and The Moor LDI (Moor Instruments, Devon, UK) [49], utilise a laser beam to scan several points across a tissue surface and generates a 2D colourcoded image that is correlated to the blood flow [49].
They are primarily used for burn depth assessment but have been utilised for scar evaluation $[49,59]$. The method is, however, hampered by long measurement times and low resolution [57]. LSI and LSPI are alternative perfusion monitoring techniques that generate rapid, high-resolution images of tissue. As red blood cells move during circulation, dynamic interference patterns that change with time are created. Blood flow maps can then be created from the coherent light that is reflected from stationary tissue, generating a high contrasted speckle pattern that remains static in time. As indicated previously, high measurements reflect high blood flow and immature/hypertrophic scars. LSI devices compare favourably with the more established LDI instruments, but offer advantages in terms of a faster scan time, higher resolutions and the ability to zoom in with increased resolution of a smaller field of view, a feature that is not possible with LDI $[57,60]$.

A major disadvantage common to all laser imaging systems are that they are not very portable (with the exception of a new commercially available laser speckle imaging device developed by Moor instruments [61]) due to their size and are often very expensive, with costs of $>£ 30,000$.

Table 2 summarises the comparison of laser devices in terms of parameter measured, reliability, correlation with clinical score and cost.

\section{Thermographic analysis of burn scars}

Thermographic cameras detect radiation in the longinfrared range of the electromagnetic spectrum (9$14 \mu \mathrm{m})$ and can be used to produce images or videos of that radiation. Thermography can be divided into passive (where the object can be imaged directly as it has a higher or lower temperature than the background) and active thermography (where an energy source is required to produce a thermal contrast between the imaged object and the background). Several studies have looked at using thermography to assess the depth of burn wounds [37, 62-64].

Our literature search however has only been able to identify one small study done in $1985(n=12)$ which utilised thermographic analysis of the scar temperature in an attempt to differentiate hypertrophic and non-hypertrophic scars [65]. No relationship between scar temperature and hypertrophic scar formation was found.

A more recent case report by Horta et al. [66] which utilised a thermography camera (FLIR SC7000 thermography camera; FLIR Systems, Wilsonville, OR, USA) showed that factors such as muscle activity or the lack of mucosa, cartilage and bone can influence the thermographic reading of scars rather than the degree of hypertrophy itself. This further complicates the use of thermography to objectively quantify scars. 
Table 1 Comparison of colour measurement devices in terms of parameter measured, reliability, correlation with clinical score and cost

\begin{tabular}{|c|c|c|c|c|c|c|c|c|}
\hline Device & Company & Parameter & Intra-rater Reliability & Inter-rater reliability & Correlation with clinical score & Cost & Portability & References \\
\hline $\begin{array}{l}\text { Computerised } \\
\text { colour analysis }\end{array}$ & $\begin{array}{l}\text { Sony Hi-8 } \\
\text { Handycam } \\
\text { CCD-TR } \\
705 \text { E video } \\
\text { camera } \\
\text { recorder } \\
\text { and Adobe } \\
\text { Photoshop }\end{array}$ & $\begin{array}{l}\text { Hue, saturation, } \\
\text { value }\end{array}$ & No data & No data & $\begin{array}{l}\text { VSS Vascularity score significantly } \\
\text { correlated with hue }(r=0.311) \text { and } \\
\text { saturation }(r=0.35)(p<0.051) \text {, index } \\
\text { with hue and saturation combined } \\
\text { correlated even better }(r=0.42) \text {. }\end{array}$ & $£ 5000-10,000$ & Yes & Davey et al. 1999 [16]. \\
\hline $\begin{array}{l}\text { Computerised } \\
\text { colour analysis }\end{array}$ & $\begin{array}{l}\text { Nikon D70 } \\
\text { camera and } \\
\text { Adobe } \\
\text { photoshop }\end{array}$ & $\begin{array}{l}\text { Tristimulus } \\
\text { colorimetry }\left(L^{*} a^{*} b^{*}\right)\end{array}$ & $0.95-0.99$ & $0.94-0.95$ & $\begin{array}{l}\mathrm{L}^{*} \text { and } \mathrm{a}^{*} \text { values are more important } \\
\text { than } \mathrm{b}^{*} \text { values in distinguishing } \\
\text { colour features between normal skin } \\
\text { and scars. }\end{array}$ & No data & Yes & Cheon et al. 2010 [32] \\
\hline $\begin{array}{l}\text { Labscan XE (non- } \\
\text { portable version) }\end{array}$ & Hunterlab & $\begin{array}{l}\text { Tristimulus } \\
\text { colorimetry }\left(L^{*} a^{*} b^{*}\right), \\
\text { chroma and hue. }\end{array}$ & Good (0.95-0.99) & $\begin{array}{l}\text { Acceptable to good } \\
(0.50-0.99 \text {, outlier } \\
\text { low value of } 0.50 \text { for } \\
a^{*} \text { [ranged from } 0.01 \\
\text { to } 0.77 \text { ]) }\end{array}$ & $\begin{array}{l}\mathrm{L}^{*}, \mathrm{a}^{*}, \mathrm{~b}^{*} \text { and hue had moderate to } \\
\text { strong correlation with VSS } \\
\text { pigmentation and vascularity scores. } \\
\text { Chroma had low correlation with } \\
\text { pigmentation and vascularity } \\
(r=-0.40 \text { and }-0.17)\end{array}$ & $>£ 10,000$ & Poor & Li-Tsang et al. 2003 [17] \\
\hline $\begin{array}{l}\text { Labscan XE } \\
\text { (portable version) }\end{array}$ & Hunterlab & $\begin{array}{l}\text { Tristimulus } \\
\text { colorimetry }\left(L^{*} a^{*} b^{*}\right)\end{array}$ & No data & No data & No data & $£ 5000-10,000$ & Yes & Li-Tsang et al. 2005 [102] \\
\hline Chromameter & $\begin{array}{l}\text { Konica- } \\
\text { Minolta }\end{array}$ & $\begin{array}{l}\text { Tristimulus } \\
\text { colorimetry }\left(L^{*} a^{*} b^{*}\right)\end{array}$ & $\begin{array}{l}\text { Acceptable } \\
(0.73-0.89)\end{array}$ & Good (0.91-0.97) & $\begin{array}{l}\text { Unable to differentiate between } \\
\text { hypo- and hyperpigmented scars } \\
\text { and normal and 'red' skin (On Seattle, } \\
\text { Hamilton and Vancouver scar scales) }\end{array}$ & $£ 5000-10,000$ & Yes & $\begin{array}{l}\text { Draaijers et al. } 2004 \text { [15], } \\
\text { Oliveira et al. } 2005 \text { [29], }\end{array}$ \\
\hline Eykona 3D camera & Fuel 3D & $\begin{array}{l}\text { Tristimulus } \\
\left.\text { colorimetry ( } L^{*} a^{*} b^{*}\right)\end{array}$ & No data & No data & $\begin{array}{l}\text { Good correlation (Manchester scar } \\
\text { scale) }\end{array}$ & $\begin{array}{l}<£ 5000 \text { (not } \\
\text { including targets) }\end{array}$ & Yes & Hallam et al 2013 [25] \\
\hline Colorimeter & $\begin{array}{l}\text { Courage + } \\
\text { Khazaka }\end{array}$ & $\begin{array}{l}\text { Tristimulus } \\
\text { colorimetry }\left(L^{*} a^{*} b^{*}\right) \\
\text { and ITA (Individual } \\
\text { Typology Angle) }\end{array}$ & No data & Good (0.91-98) & No data & $\begin{array}{l}£ 5000-10,000 \\
\text { (including cost of } \\
\text { hub) }\end{array}$ & Yes & van der Wal et al. 2013 [20]. \\
\hline Mexameter & $\begin{array}{l}\text { Courage }+ \\
\text { Khazaka }\end{array}$ & $\begin{array}{l}\text { Narrow-band } \\
\text { spectrophotometry } \\
\text { (melanin and } \\
\text { erythema) }\end{array}$ & $\begin{array}{l}\text { Good for melanin } \\
(0.89-0.97) \text { and } \\
\text { acceptable for } \\
\text { erythema }(0.74-0.90)\end{array}$ & $\begin{array}{l}\text { Good for melanin } \\
(0.95) \text { and erythema } \\
(0.82-0.85)\end{array}$ & No data & $<£ 5000$ & Yes & $\begin{array}{l}\text { Nedelec et al. } 2008 \text { (I) [30], } \\
\text { Nedelec et al. } 2008 \text { (II) } \\
\text { [106], van der Wal et al. } \\
2013 \text { [20]. }\end{array}$ \\
\hline $\begin{array}{l}\text { Dermaspectrometer/ } \\
\text { DSM II Colorimeter }\end{array}$ & Cortex & $\begin{array}{l}\text { Both tristimulus } \\
\text { colorimetry and } \\
\text { narrow-band } \\
\text { spectrophotometry }\end{array}$ & 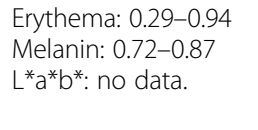 & 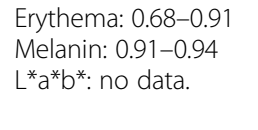 & $\begin{array}{l}\text { Erythema: Moderate but significant } \\
r=0.50(<0.001) \\
\text { Melanin: weak but significant } r=0.32 \\
(0.02)-0.63(<0.001)\end{array}$ & $<£ 5000$ & Yes & $\begin{array}{l}\text { Gankande et al. } 2014 \text { [6], } \\
\text { Gankande et al. } 2015 \text { [248], } \\
\text { van der Wal et al. } 2013 \text { [20], } \\
\text { Oliveira et al. } 2005 \text { [29]. }\end{array}$ \\
\hline
\end{tabular}


Table 1 Comparison of colour measurement devices in terms of parameter measured, reliability, correlation with clinical score and cost (Continued)

\begin{tabular}{|c|c|c|c|c|c|c|c|c|}
\hline $\begin{array}{l}\text { Standardised digital } \\
\text { imaging (SDI) + } \\
\text { Spectral modelling } \\
\text { (SpM) }\end{array}$ & $\begin{array}{l}\text { Custom } \\
\text { made }\end{array}$ & $\begin{array}{l}\text { Estimated } \\
\text { concentration } \\
\text { change of } \\
\text { haemoglobin and } \\
\text { melanin }\end{array}$ & $\begin{array}{l}\text { Good for } \\
\text { haemoglobin }(0.875) \\
\text { and melanin }(0.886)\end{array}$ & $\begin{array}{l}\text { Good for } \\
\text { haemoglobin (0.955) } \\
\text { and melanin }(0.959)\end{array}$ & $\begin{array}{l}\text { Acceptable correlation with POSAS } \\
(0.63 \text { for haemoglobin, } 0.60 \text { for } \\
\text { melanin) and VSS ( } 0.74 \text { for } \\
\text { haemoglobin, } 0.53 \text { for melanin) }\end{array}$ & $\begin{array}{l}<£ 5000 \text { (but not } \\
\text { commercially } \\
\text { available) }\end{array}$ & Yes & Kaartinen et al. $2011[7,8]$ \\
\hline \multirow[t]{2}{*}{ Dermoscopy } & \multirow{2}{*}{$\begin{array}{l}\text { Hong Kong } \\
\text { Productivity } \\
\text { Council }\end{array}$} & \multirow{2}{*}{$\begin{array}{l}\text { RGB values: } \\
\text { lightness and } \\
\text { redness }\end{array}$} & Redness: 0.980 & Redness: 0.93 & \multirow[b]{2}{*}{$\begin{array}{l}\text { Strong correlation between the VSS } \\
\text { scores of vascularity and the RGB } \\
\text { values of redness obtained from the } \\
\text { dermoscope }(r=0.625, p<0.01) \text {. } \\
\text { Strong correlation also found } \\
\text { between transformed VSS scores of } \\
\text { pigmentation and the lightness of } \\
\text { the dermoscope pictures when } \\
\text { vascularity was blanched out } \\
\text { (i.e. when measuring pure } \\
\text { pigmentation) }(r=0.783, p<0.01) \text {. }\end{array}$} & \multirow[t]{2}{*}{ No data } & \multirow[t]{2}{*}{ Yes } & \multirow[t]{2}{*}{ Wei et al. 2015 [238]. } \\
\hline & & & Lightness: 0.965 & Lightness: 0.871 & & & & \\
\hline
\end{tabular}

$R G B=$ red, green and blue 
Table 2 Comparison of laser devices in terms of parameter measured, reliability, correlation with clinical score and cost

\begin{tabular}{|c|c|c|c|c|c|c|c|c|}
\hline Device & Company & Parameter & $\begin{array}{l}\text { Intra-rater } \\
\text { reliability }\end{array}$ & $\begin{array}{l}\text { Inter-rater } \\
\text { reliability }\end{array}$ & Correlation with clinical score & Cost & Portability & References \\
\hline $\begin{array}{l}\text { Laser Doppler } \\
\text { Flowmeter }\end{array}$ & Moor & Blood flow & No data & No data & $\begin{array}{l}\text { LDF showed significant difference in blood } \\
\text { flow within hypertrophic and keloid scars } \\
\text { and normal skin (2.6-2.8-fold higher). }\end{array}$ & $>£ 30,000$ & Poor & $\begin{array}{l}\text { Clark et al. } 1996 \\
\text { [56], Timar-Banu } \\
\text { et al. } 2001 \text { [53]. }\end{array}$ \\
\hline $\begin{array}{l}\text { Laser Doppler } \\
\text { Imaging }\end{array}$ & $\begin{array}{l}\text { Lisca, } \\
\text { Moor }\end{array}$ & $\begin{array}{l}\text { Blood flow } \\
\text { (red and } \\
\text { near infrared } \\
\text { wavelengths) }\end{array}$ & No data & No data & $\begin{array}{l}\text { Correlations with clinically assessed grades } \\
\text { (VSS) of pigment, vascularity, pliability, } \\
\text { and height ranged from } r^{2}=0.63 \text { to } 0.95 \text {. }\end{array}$ & $>£ 30,000$ & Poor & $\begin{array}{l}\text { Stewart et al. } 2005 \\
\text { [60] Bray et al. } \\
2003 \text { [49]. }\end{array}$ \\
\hline $\begin{array}{l}\text { Laser Speckle } \\
\text { Perfusion } \\
\text { Imaging }\end{array}$ & Moor & Blood flow & No data & No data & $\begin{array}{l}\text { Correlations with clinically assessed grades } \\
\text { (VSS) of pigment, vascularity, pliability, } \\
\text { and height ranged from } r^{2}=0.73 \text { to } 0.94 \text {. }\end{array}$ & $>£ 30,000$ & Poor & $\begin{array}{l}\text { Stewart et al. } \\
2005 \text { [60] }\end{array}$ \\
\hline
\end{tabular}

$L D F=$ Laser Doppler Flowmetry; VSS = Vancouver Scar Scale

\section{Scar dimensions}

\section{Surface area and volume}

Planimetry is the measure of the surface area of a scar and, when done over time, can be used to assess the contraction or expansion of a scar.

The most basic method of planimetry, that does not require specialist equipment or trained personnel, is the linear method where the maximum length and width of the wound is measured directly on the patient and the surface area is then calculated by multiplying the maximum length and width. As can be expected, this technique is inaccurate as scars are rarely rectangular or square in shape and will produce results that are significantly different from those obtained with tracing and photography methods [67].

The second method involves the tracing of scar margins either on sheets of paper, clear plastic film or any transparent non-stretchable material $[27,46]$. The surface area traced on these sheets can then be calculated by outlining wound margin with the tip of a planimeter (Koizuni Sokk Manufacturing Ltd., Nagoaka-shi, Japan) [67] or by digitising the tracings on these sheets and using software such as NIS-Elements (Nikon, Amstelveen, The Netherlands) [27] , ImageJ [68] or Digimizer software [69] to calculate the surface area. Dedicated systems have also been developed such as the Visitrak (Smith \& Nephew) which have been shown to have high intra- and inter-rater reliability and high validity in the measurement of the surface area of ulcers [70] although the maximum size of the area that can be measured at a time is limited by the disposable tracing grid used $(14 \mathrm{~cm} \times 14 \mathrm{~cm})$.

The third method uses digital photography combined with image analysing programmes such as ImageJ, Image Tool (C.D. Wilcox and colleagues, San Antonio, TX, USA) [29] or Adobe Photoshop (Adobe Systems Inc., San Jose, California, USA) [71] to measure the surface area. A significant problem with $2 \mathrm{D}$ photography is that it is subject to parallax errors and projecting a threedimensional object onto a two-dimensional image. Due to this, the 2D surface area (or planimetric area) calculated does not take into account the wound surface topography and will nearly always underestimate the true three-dimensional surface area (see Fig. 4).

With smaller scars, this error would be small but will increase as the size increases. A study by van Zuijlen et al. compared the direct and indirect (through 2D photography) tracing methods [71]. It found that both techniques were reliable $(r \geq 0.82, p<.001)$ for surface lesions with a scar surface area of $25 \mathrm{~cm}^{2}$, but planimetry by photography was superior to planimetry by direct tracing in respect to inter-observer reliability for surface lesions of 50 and $75 \mathrm{~cm}^{2}$, with increasing scar size resulting in decreasing inter-observer reliability. However, planimetry by direct tracing was more accurate on curved surfaces (e.g. forearm), with a statistically significant reduction of the surface area obtained when compared to results with planimetry after photography. The use of photography [29, 43] to measure surface area, although useful, is subject to variance caused by lighting conditions, distance and camera settings and does not provide any information on volume.

Three-dimensional (3D) measurement systems can overcome the limitation of $2 \mathrm{D}$ photograph, and in addition to

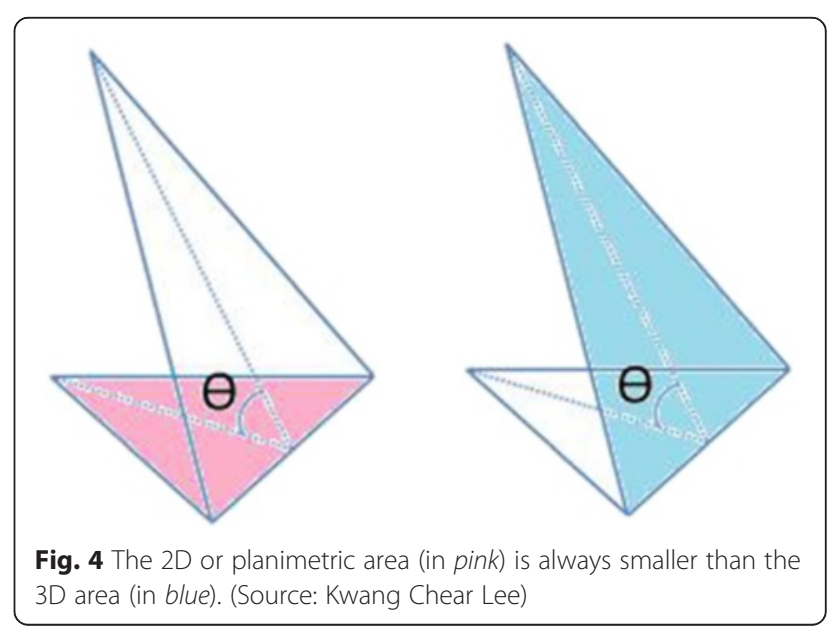


surface area measurements, the 3D camera systems are also able to measure the volume of scars much more quickly and easily compared to traditional moulage and moulding [72] methods.

A 3D image can be achieved via various methods. A method that is commonly used in the medical is stereophotogrammetry. These systems are non-contact and involve taking two or more pictures using either one or multiple cameras which can be on the same device (e.g. Eykona wound measurement system, Fuel 3D, UK [25]) or separate devices (e.g. 3D MD static systems, 3dMD, USA [73]). Some authors have even developed their own systems with standard cameras (e.g. Stereoimage optical topometer (Korea University, Seoul, South Korea) with PC vision plus (AES, Sydney, Australia)) [74]. Other devices utilise mirrors to achieve a similar effect for, e.g. LifeViz I, II, Mini or Micro (Quantificare S.A., Sophia Antipolis, France) [75, 76] and Vectra H1 3D imaging system (Canfield Scientific Inc, Fairfield, NJ, USA) [77-80]. Other systems utilise the projection of a complex speckled pattern in combination with a colour camera to produce the 3D images [81].

These software are able to provide information about the surface area [82] and tissue volume above the skin [83] (including correction for curved surfaces) as well as geometry, texture and, as mentioned above, the colour of scars for which the performance of the Eykona device has been shown to compare favourably with the subjective Manchester Scar Scale (MSS) [25]. These devices share a few common drawbacks. Firstly, none of them have been validated in scar studies, but their ability to measure the area [83-85] and volume of wounds and tissue (e.g. breasts [82]) has been shown in other non-scar related studies. Additionally, the maximum area that can be imaged is limited to the size of about an A4 size sheet of paper which is not ideal for large burns scars. Furthermore, although stitching of images is possible, this really only applies to the face as it is easy to identify anchor points such as the eyes and nose, but to do so for other highly curved surfaces such as the forearm or the whole body would be technically challenging and time consuming and requires high-end hardware and thus a true $360^{\circ}$ view would not be easily possible [80]. Hairy areas of the body can also pose a problem [80].

The Lifeviz and Vectra H1 systems have an advantage over the Eykona in that they have adjustable light-beam pointers to aid positioning and do not require one-use disposable targets which the Eykona system does but they are also significantly more expensive. Furthermore, the Eykona is no longer being developed by the company and has not been updated recently, thus its resolution is significantly lower (250 micron sampling via two $5 \mathrm{MP}$ sensors) [86] compared to the Lifeviz Mini (13.5-24 MP,
0.5-2 mm geometry resolution) [87] or Vectra H1 cameras (18 MP, $0.8 \mathrm{~mm}$ geometry resolution) [88].

More recently, light field or plenoptic technology has been introduced. Cameras utilising this technology (Raytrix 3D camera systems, Raytrix, Germany [89]) capture information about the intensity and also direction of the light rays utilising an array of micro-lenses [89]. The images or data are then processed and merged using dedicated image analysis software into a single 3D image. Additionally, other commonly used 3D imaging techniques include structured light scanner systems (or coherence scanning interferometery) such as the Artec [90] (Artec Group,USA/Luxemborg/Russia) and ATOS series of scanners [91], and laser scanning devices such as the Minolta Vivid 900 or 910 3D linear laser scanner (Konica-Minolta, Osaka, Japan) [92, 93]. Whole body scanners such as the Cyberware Whole Body Color 3D Scanner (Model WBX, Cyberware Inc, Monterey, California) [94] are also available. These other systems have the ability to scan much larger areas (up to the size of a car with some systems) compared to the Eykona, Lifeviz and Vectra; however, they have not been specifically manufactured or optimised for medical use. For example with the Artec Eva system, the software supplied is able to calculate the surface area and volume of an object on a flat surface but not on curved surfaces. Specialised 3D analysis software such as Rapidform (Inus technology, Seoul, South Korea) [93] is required to measure and quantify surface area and volume information obtained from these scans. The authors are not aware of any published studies that have validated the surface area and volume measurements produced by these devices or software.

A different approach to calculating the surface area of scars is through the use of a combination of $2 \mathrm{D}$ photography and 3D models. The Burncase 3D (RISC Software $\mathrm{GmbH}$, Austria) software has been developed for the estimation of burn surface areas primarily but it theoretically can be adapted to measure the surface area of scars. With the Burncase 3D programme, 2D photographs of the lesions are superimposed onto a $3 \mathrm{D}$ model that can be adjusted according to the height, weight, age and gender of the patient. The outline of the lesion is then traced onto the 3D model from the photographs (which can be multiple and is aided by an automated alignment algorithm that uses corresponding landmarks to allow quick matching [95]) and the software then estimates the surface area. The areas can also be classified into different categories if needed (e.g. normal and hypertrophic scar areas) and thus useful to track the progression of the wounds from time of burn through to scar formation. As it uses standardised 3D models to estimate surface area, much work is still required to validate the accuracy and precision especially in small children (currently in 
progress [96, 97]) and obese patients [95]. In a study which utilised mannequins, the inter-class correlation between the single raters of the mean percentage of artificially created burn areas was 0.988 with relative underestimations of burn wound areas of $0.4 \%$ in the child mannequin, and overestimations of 2.8 and $1.5 \%$ for the female and male mannequins when compared to areas as measured with 2D planimetry imaging [97].

Table 3 below summarises the comparison of 3D measurement devices in terms of parameter measured, reliability, correlation with clinical score and cost.

\section{Thickness}

The accuracy of subjective estimation of scar thickness has been shown to be quite low, $67 \%$ (when measured against ultrasound measured thickness) [98] and thus unreliable.

Objective thickness or height of a scar can be evaluated by measurement by 3D photography (see above) or the use of negative-positive moulage [99]. A negative-positive moulage is performed by firstly making a negative impression cast (negative moulage) of the scar using materials such as alginate, silicon, siloxane [58, 72], dental impression material [100] or plaster of paris. A positive impression cast (positive moulage) is then made by pouring a material that will harden (e.g. plaster of paris, wax) into the negative moulage. Once hardened, this positive moulage can then be measured. These techniques have some limitations and are inaccurate as the portion of the scar below the surface of the skin is not included in the measurement [101].

This limitation can be overcomed by using highfrequency $(5-20 \mathrm{MHz})$ ultrasound systems such as the Tissue Ultrasound Palpation System (TUPS; Biomedical Ultrasonic Solutions, Hong Kong) [102-105], the Dermascan C [30, 53, 106, 107] (Cortex, Hadsund, Denmark) devices, Acuson Sequoia 512 [108] (Siemens, Germany; highest frequency probe available is $10 \mathrm{MHz}$ ), HDI 5000 (Philips, Amsterdam, Netherlands) [109], and the Dermcup 2020 (Atys Medica, Soucieu-en-Jarret, France) [110]. High-frequency ultrasound systems have previously been used in many dermatological applications [111].

Ultrasound skin imaging is performed by firing an acoustic pulse into the skin and measuring the acoustic response from the skin which is picked up by an ultrasound transducer. The signals are then processed, and a cross-sectional image is produced which represents an intensity/amplitude analysis of these returned signals. Areas with small changes in density between structures such as scar tissue and fat will produce a low reflection and be visualised as dark colours, whereas areas with significant changes in density between structures (e.g. healthy dermis) will be visualised as bright areas (Fig. 5).
An advantage of ultrasound systems are that they allow real-time measurement on changes of scar thickness upon pressure loading [112]. Additionally, high-frequency ultrasound systems will also allow the identification of aberrant structures within the scars which may affect treatment [113].

The frequency of the ultrasound determines the resolution and penetrance of the measurement. A low frequency will allow deeper penetration but lower resolution images, whereas a higher frequency will have a shallower penetrance but produce higher resolution images (Fig. 6). High-frequency ultrasound systems utilise a frequency above $18 \mathrm{MHz}$ to obtain images of the skin structure with acceptable resolution. In earlier studies, $7.5-\mathrm{MHz}$ probes have been used to measure and track the change in thickness of healing burn scars [101, 114]. These lower frequency systems allow evaluation of deeper tissues (penetration of $>15 \mathrm{~mm}$ ) but have a low resolution of $2-3 \mathrm{~mm}$ which may not be sufficient for the evaluation of superficial skin structures [115]. More recently, higher frequency ultrasound probes $(20 \mathrm{MHz})$ have been used to allow more detailed images of the structures of the skin to be visualised, producing higher resolutions of at least $50 \mu \mathrm{m}$ [115-117]. Probes with frequencies below $50 \mathrm{MHz}$ are advised as systems with higher frequencies and will not be able to penetrate to the average depth of hypertrophic scars which is around $4-5 \mathrm{~mm}$.

It is advisable to always check with the manufacturer the actual penetrance of the systems as cheaper portable ultrasound systems (e.g. Dermalab USB Ultrasound, Cortex, Hadsund, Denmark) only penetrate a maximum of $3.4 \mathrm{~mm}$ despite being a $20-\mathrm{MHz}$ system [6].

These high-frequency ultrasound devices both show good inter-observer reliability and moderately correlate with the modified VSS [118] (modified version of the Vancouver Scar Scale by Nedelec et al.), with the Dermascan $\mathrm{C}$ system having the better correlation of the two (0.41-0.50 versus 0.34). It has to be noted that the VSS measures clinical scar thickness (i.e. the thickness of the scar that is above the surface of the skin), whereas the two ultrasound systems measure histological thickness (i.e. the whole thickness of the scar above and below the surface of the skin). The Dermascan system would thus be preferred, although it is more expensive than the TUPS (however at the time of writing, there was no method to purchase the TUPS from their website). Other ultrasound systems that are commercially available include the Acuson Sequoia 512 (Siemens, Germany) [119], Episcan(Longport, USA) [120, 121] and the DUB ${ }^{\circ}$ SkinScanner (EOTech, France) [122], although at present there are no published studies that have utilised these for scar measurement.

Ultrasound systems that can capture a 3D image of a scar have now become commercially available, albeit 
Table 3 Comparison of 3D measurement devices in terms of parameter measured, reliability, correlation with clinical score and cost

\begin{tabular}{|c|c|c|c|c|c|c|c|c|}
\hline Device & Company & Parameter & $\begin{array}{l}\text { Intra-rater } \\
\text { Reliability }\end{array}$ & $\begin{array}{l}\text { Inter-rater } \\
\text { reliability }\end{array}$ & Correlation with clinical score & Cost & Portability & References \\
\hline \multirow[t]{2}{*}{ Eykona 3D camera } & \multirow[t]{2}{*}{ Fuel 3D } & \multirow{2}{*}{$\begin{array}{l}\text { Surface area } \\
\text { and volume }\end{array}$} & \multirow{2}{*}{$\begin{array}{l}\text { Intra-operator } \\
\text { variability: area: } \\
0.9 \% \text {; volume: } \\
4.0 \%\end{array}$} & \multirow{2}{*}{$\begin{array}{l}\text { Intra-operator } \\
\text { variability: area: } \\
1.7 \% \text {; volume: } \\
4.0 \%\end{array}$} & \multirow[t]{2}{*}{ No data } & $<£ 5000$ for the camera unit. & \multirow[t]{2}{*}{ Yes } & \multirow{2}{*}{$\begin{array}{l}\text { Paterson et al. (Eykona } \\
\text { Medical Imaging FAQ) [86]. }\end{array}$} \\
\hline & & & & & & $\begin{array}{l}\sim £ 3 \text { for each disposable } \\
\text { target but device can now } \\
\text { be configured to use } \\
\text { reusable targets. }\end{array}$ & & \\
\hline \multirow[t]{2}{*}{ Lifeviz I, II, Micro } & \multirow[t]{2}{*}{ Quantificare } & \multirow[t]{2}{*}{$\begin{array}{l}\text { Surface area } \\
\text { and volume }\end{array}$} & \multirow[t]{2}{*}{ No data } & $\begin{array}{l}\text { Surface area: } \\
\text { ICC }=0.99 \\
\text { (Coefficient } \\
\text { of variation } \\
5.9-6.8 \%)\end{array}$ & \multirow{2}{*}{$\begin{array}{l}\text { Surface area: Excellent level of } \\
\text { agreement with Visitrak (ICC } 0.96, \\
95 \% \text { CI } 0.93,0.97) \text {, however greater } \\
\text { level of variability in larger wounds } \\
\text { especially circumferential wounds. } \\
\text { Volume: } P^{2}=0.9678 \text { when correlated } \\
\text { with actual volumes of model scars }\end{array}$} & \multirow[t]{2}{*}{$£ 10,000-£ 15,000$} & \multirow[t]{2}{*}{ Yes } & \multirow[t]{2}{*}{$\begin{array}{l}\text { Lumenta et al. } 2011 \text { [76], } \\
\text { Stekelenburg et al. } 2013 \text { [75] }\end{array}$} \\
\hline & & & & Volume: no data & & & & \\
\hline Vectra H1 & $\begin{array}{l}\text { Canfield } \\
\text { Imaging } \\
\text { Systems Inc. }\end{array}$ & $\begin{array}{l}\text { Surface area } \\
\text { and volume }\end{array}$ & No data & No data & No data & $£ 10,000-£ 15,000$ & Yes & $\begin{array}{l}\text { Tzou et al. } 2014 \text { [256], } \\
\text { Urbanova et al. } 2015 \text { [80]. }\end{array}$ \\
\hline Artec Eva & Artec & $\begin{array}{l}\text { Surface area } \\
\text { and volume }\end{array}$ & No data & No data & No data & $\begin{array}{l}<£ 10,000 \text { (depends } \\
\text { on package) }\end{array}$ & Yes & $\mathrm{N} / \mathrm{a}$ \\
\hline $\begin{array}{l}\text { Minolta Vivid } 910 \text { 3D } \\
\text { linear laser scanner }\end{array}$ & Konica-Minolta & $\begin{array}{l}\text { Surface area } \\
\text { and volume }\end{array}$ & No data & No data & No data & $>£ 15,000$ & Yes & Taylor et al. 2007 [93]. \\
\hline $\begin{array}{l}\text { Moulding (positive- } \\
\text { negative moulage) }\end{array}$ & N/a & Volume & $\mathrm{ICC}=0.921-0.995$ & $\mathrm{ICC}=0.759-0.977$ & No data & $\begin{array}{l}\text { Dependent on moulding } \\
\text { material and measurement } \\
\text { techniques used }\end{array}$ & Yes & Berman et al. 2015 [72]. \\
\hline
\end{tabular}



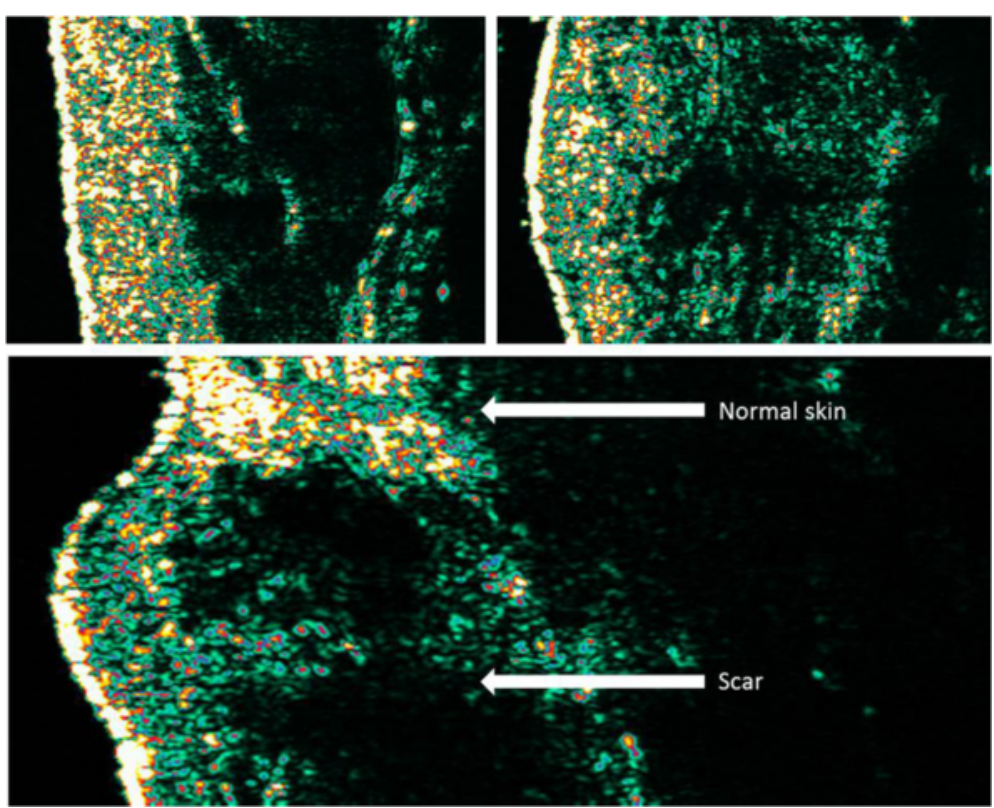

Fig. 5 High-frequency ultrasound image of normal skin (top left, site: forearm). High-frequency ultrasound image of hypertrophic scar (top right, site: shoulder). High-frequency ultrasound image of normal skin (top) and adjacent scar tissue (bottom) (bottom, site: shoulder). Note that the scars appear more hypo-echoic as it is more homogenic and thus appears darker. Colours represent the intensity of the acoustic signal with bright colours (yellow) representing high-intensity and darker colours (e.g. green, black) representing low-intensity areas. (Source: Kwang Chear Lee, taken with Dermascan C)

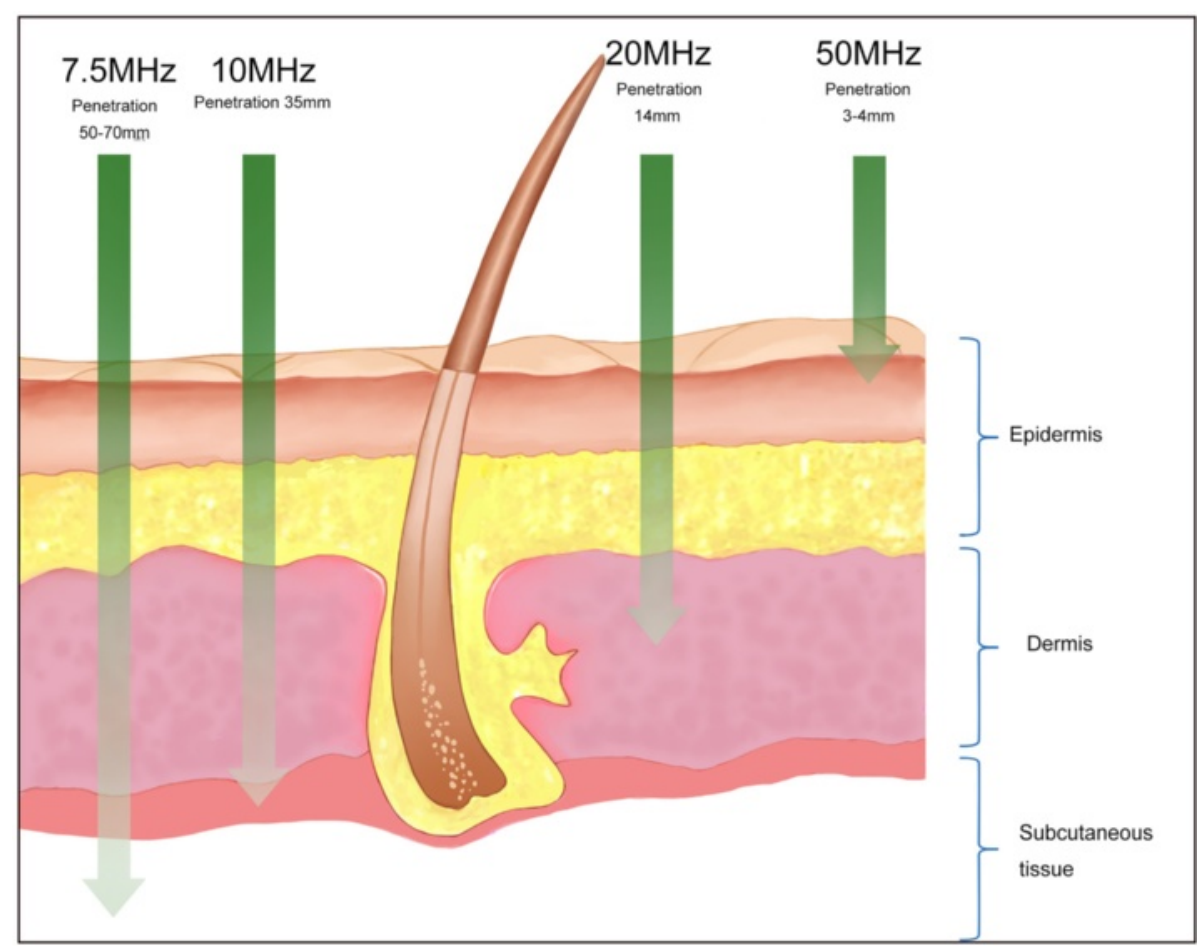

Fig. 6 Different frequencies of ultrasounds and their penetrance into the skin. (Source: Kwang Chear Lee, adapted from image from http://www.eotech.fr/Fiches/produits/107_DUB_Brochure_English_DB10_2012_O.pdf) 
only from one company (Cortex, Hadsund, Denmark). However, this system has not been trialled on scars, is limited to a small measurement area $(22 \times 22 \mathrm{~mm})$ and costs significantly more compared to the $2 \mathrm{D}$ system (Table 4 ).

A summary of the different ultrasound systems is given in Table 4.

\section{Texture}

\section{Skin topography}

Scar roughness has a significant effect on the patient's and observer's opinion of the scar [4]. Indirect methods of measuring skin topography that involve creating a negative replica of the skin using materials such as polymers (e.g. Silflo silicon polymer; Flexico Developments Ltd., Hertfordshire, UK [123]) and then further analysing this with devices (e.g. mechanical, optical, laser or interference fringe projection profilometry [123-125]), although accurate can be very time consuming and not appropriate for clinical use [126]. Transparency profilometry (using the Visiometer; Courage + Khazaka, Germany) uses the Silflo silicon polymer but analysis is much easier and quicker [127, 128]. However, these indirect measurement techniques have been clinimetrically evaluated [123].

The Phaseshift Rapid In Vivo Measurement Of the Skin [129] (PRIMOS; Omniscan, GFMesstechnik GmbH; Germany) and the Visioscan VC 98 (Courage + Khazaka, Germany) are the only devices currently on the market that can be used to measure skin topography directly, but only the PRIMOS system has published studies in scars.

Three parameters were used for the evaluation of the PRIMOS system by Bloemen et al [129]. These were the peak count (PC, number of peaks per unit length), arithmetic mean of surface area roughness (Sa, in micrometers) and the mean of five highest peaks and five deepest valleys form entire measurement ( $\mathrm{Sz}$, in milimeters).

The PRIMOS has been shown to have excellent intraobserver and inter-observer reliability on both normal skin and scars and a high correlation with the relief score of the Patient and Observer Scar Assessment Scale (POSAS) on scar (The relief score in the POSAS questionnaire is the rating given by patients and clinicians on the surface irregularity of their scar compared to normal skin).

An added advantage of the PRIMOS system is that it can also be used to measure scar height [130].

The Visioscan VC 98 is a UVA-light video camera with high resolution that utilises the Surface Evaluation for Living Skin (SELS) method to evaluate the roughness of skin [131]. This method analyses the grey level distribution of the image captures and allows the calculation of four clinical parameters to quantitatively and qualitatively describe the skin surface as an index: skin smoothness (Sesm), skin roughness (Ser), scaliness (Sesc), wrinkles (Sew). As mentioned previously, this system has not been used to evaluate scars but has shown a high reliability for the measure of in vivo skin roughness in normal skin [131]. However, the Visioscan only measures an area of $6 \times 8 \mathrm{~mm}$ at a time which is probably too small for the analysis of the irregularity of a burn scar.

The aforementioned 3D camera systems can potentially also be used for skin topography analysis. However, these systems are already becoming the preferred devices in the clinic for scar surface area measurement as they are significantly more portable than the PRIMOS system although portable versions of the PRIMOS system are now commercially available (PRIMOS lite, GFMesstechnik $\mathrm{GmbH}$; Germany). Lumenta et al. showed that the Lifeviz Micro 3D camera system (Quantificare S.A., Sophia Antipolis, France) was able to detect surface irregularities (SI) much better than subjective visual assessment which failed to detect at least half of the broader changes in SI of $\geq 34 \%$ [76]. Kim et al. utilised a self-developed 3D camera system (Stereoimage Optical Topometer, Korea University, Seoul, Korea) to calculate the mean surface area roughness $(\mathrm{Sa})$ and root mean square roughness $(\mathrm{Sq})$ for acne scars which were found to have a positive correlation with visual gradings (Spearman correlation coefficient $\rho=0.463$ and 0.438 respectively, $p<0.001)$. Table 5 below summarises the surface topography devices.

\section{Biomechanical properties \\ Pliability, elasticity or stiffness}

The biomechanical properties of skin can be measured with a variety of methods including suction, tonometry, torsion, adherence and reviscometry. Other methods include elastometry, ballistometry, quantitative electrical methods (dielectric measurements and bio-impedance) [132] as well as ultrasound and MRI techniques [133].

Non-suction extension methods Older methods of measuring skin elasticity relied on extension methods (i.e. physical stretching) to measure the viscoelastic properties of skin tissue using ex vivo [134] or in vivo extensometers [135-140] or elastometers [58], which utilises a constant-tension spring and a strain gauge to distract two points on the skin $[58,141]$. The majority of these devices suffer from an unwanted peripheral force contribution due to the deformation of surrounding tissues during measurement which can lead to reduced accuracy and reproducibility of results, although newer designs have sought to improve their accuracy [137].

Suction extension methods Extension of the skin by suction is the method used by devices such as the Cutometer [18, 28, 106, 142-153] (Courage + Khazaka, Germany) and the DermaLab elasticity probe [144, 154] 
Table 4 Comparison of ultrasound devices in terms of parameter measured, reliability, correlation with clinical score and cost

\begin{tabular}{|c|c|c|c|c|c|c|c|c|}
\hline Device & Company & Parameter & Intra-rater reliability & Inter-rater reliability & Correlation with clinical score & Cost & Portability & References \\
\hline Dermascan C (2D) & Cortex & Thickness (2D) & $I C C=0.91-0.93$ & $I C C=0.90-0.91$ & $\begin{array}{l}\text { Modified VSS and ultrasound } \\
\text { thickness: Spearman's } r=0.41-0.50\end{array}$ & $£ 15,000-20,000$ & Yes & Nedelec et al. 2008 [30, 106] \\
\hline Dermalab USB (2D) & Cortex & Thickness (2D) & $I C C=0.92-0.97$ & $I C C=0.86-0.98$ & No data & $<£ 10,000$ & Yes & Gankande et al. 2014 [6]. \\
\hline Dermascan C (3D) & Cortex & Thickness (3D) & No data & No data & No data & $£ 30,000-40,000$ & Yes & $\mathrm{N} / \mathrm{a}$ \\
\hline $\begin{array}{l}\text { Tissue ultrasound } \\
\text { palpation system }\end{array}$ & $\begin{array}{l}\text { Biomedical } \\
\text { Ultrasonic } \\
\text { Solutions }\end{array}$ & Thickness (2D) & $\mathrm{ICC}=0.98$ & $\mathrm{ICC}=0.84$ & $\begin{array}{l}\text { Spearman Correlation of } 0.42 \\
\text { between VSS thickness score } \\
\text { and TUPS measurement }(p<0.01) \text {, } \\
\text { and } r=0.34(p<0.01) \text { between } \\
\text { VSS total score and TUPS. }\end{array}$ & $\begin{array}{l}\text { Not currently } \\
\text { commercially } \\
\text { available. }\end{array}$ & Yes & Lau et al. 2005 [103]. \\
\hline
\end{tabular}

$2 D=$ two-dimensional; $3 D$ = three-dimensional; ICC = intra-class correlation coefficient; $V S S$ = Vancouver Scar Scale; TUPS = Tissue Ultrasound Palpation System 
Table 5 Comparison of surface topography measuring devices in terms of parameter measured, reliability, correlation with clinical score and cost

\begin{tabular}{|c|c|c|c|c|c|c|c|c|}
\hline Device & Company & Parameter & Intra-rater reliability & Inter-rater reliability & Correlation with clinical score & Cost & Portability & References \\
\hline PRIMOS & GFMesstechnik & $\begin{array}{l}\text { Surface roughness } \\
(\mathrm{PC}, \mathrm{Sa}, \mathrm{Sz})\end{array}$ & $\begin{array}{l}\text { ICC of PC =0.97, } \\
\mathrm{Sa}=0.99, \mathrm{Sz}=0.98\end{array}$ & $\begin{array}{l}\text { ICC of } \mathrm{PC}=0.9 \\
\mathrm{Sa}=0.96, \mathrm{Sz}=0.94\end{array}$ & $\begin{array}{l}\text { Correlation with POSAS: } \\
r=0.617(p<0.001)\end{array}$ & $£ 17,000-£ 14,000$ & Yes & Bloemen et al. 2011 [129]. \\
\hline Visioscan VC 98 & Courage + Khazaka & $\begin{array}{l}\text { Skin parameters } \\
\text { (Sesm, Ser, Sesc, Sew) }\end{array}$ & $\begin{array}{l}\text { Not been used } \\
\text { in scars }\end{array}$ & $\begin{array}{l}\text { Not been used } \\
\text { in scars }\end{array}$ & Not been used in scars & $£ 5000-£ 10,000$ & Yes & $\mathrm{N} / \mathrm{a}$ \\
\hline Eykona 3D camera & Fuel 3D & $\begin{array}{l}\text { Not been used } \\
\text { in scars }\end{array}$ & $\begin{array}{l}\text { Not been used } \\
\text { in scars }\end{array}$ & $\begin{array}{l}\text { Not been used } \\
\text { in scars }\end{array}$ & Not been used in scars & $<£ 5000$ & Yes & N/a \\
\hline Lifeviz Micro & Quantificare & Surface Irregularity & No data & No data & $\begin{array}{l}\text { Performed better than } \\
\text { subjective visual } \\
\text { assessment }\end{array}$ & $£ 10,000-£ 15,000$ & Yes & Lumenta et al. 2011 [76]. \\
\hline
\end{tabular}

PRIMOS = Phaseshift Rapid In Vivo Measurement Of the Skin; ICC = intra-class correlation coefficient; $P C=$ peak count; $S a=$ mean surface area roughness; $S z=$ mean of five highest peaks and five deepest valleys; POSAS = Patient and Observer Scar Assessment Scale 
(Cortex Technology, Hadsund, Denmark). With the Cutometer, negative pressure is created in the device by vacuum and the skin is drawn into the aperture of the probe and after a defined time is released again. Inside the probe, height of skin that is drawn up is determined by a non-contact optical measuring system which consists of a light source and a light receptor, as well as two prisms facing each other, which project the light from transmitter to receptor (Fig. 7). The resistance of the skin to the negative pressure (firmness) and its ability to return into its original position (elasticity) are displayed as curves (penetration depth in $\mathrm{mm} /$ time) in real time during the measurement (Fig. 8). This measurement principle allows getting information about the elastic and mechanical properties of the skin surface.

The Cutometer is reliable for measurement of the elastic and mechanical properties in scars and normal skin; however, its measurements only have a weak to moderate correlation with the pliability score of the POSAS and the subjective pliability assessment of the VSS [142]. Rennekampff et al. also suggested that the Cutometer may not be sensitive enough to pick up small changes in pliability as he found no correlation was found between subscale VSS pliability rating and Cutometer readings [155].

It was also found to be unreliable for severe scars due to a ceiling effect when rigid tissue is encountered [106].
However, the low ICC values have more to do with difficulty in relocating device to same measurement spot and the high sensitivity of the device $[30,106]$.

The mechanical parameters of the skin can be divided into absolute and relative parameters:

- Absolute (in milimeters): Ue (immediate deformation), Uv (delayed deformation), Uf (maximal deformation), Uf (immediate retraction), Ua (final detraction), R (residual deformation), R8 (visco part).

- Relative (in percentage): Ua/Uf (gross elasticity), Ur/Uf (biological elasticity), Ur/Ue (net elasticity), $\mathrm{Uv} / \mathrm{Ue}$ (viscoelastic to elastic ratio), H (hysteresis).

Absolute parameters are likely to be influenced by skin thickness which in turn is dependent on various factors such as age, gender, anatomical region thus to compare values you will need to standardise them for skin thickness using an ultrasound and this is not always possible thus the relative parameters are more useful as it can be assumed to be independent of skin thickness which allows the values in different subjects, anatomical regions and times to be compared.

Various different opinions regarding the value that should be used (Table 6); however, Draaijers et al. concluded that either Ue or Uf is sufficient for the evaluation
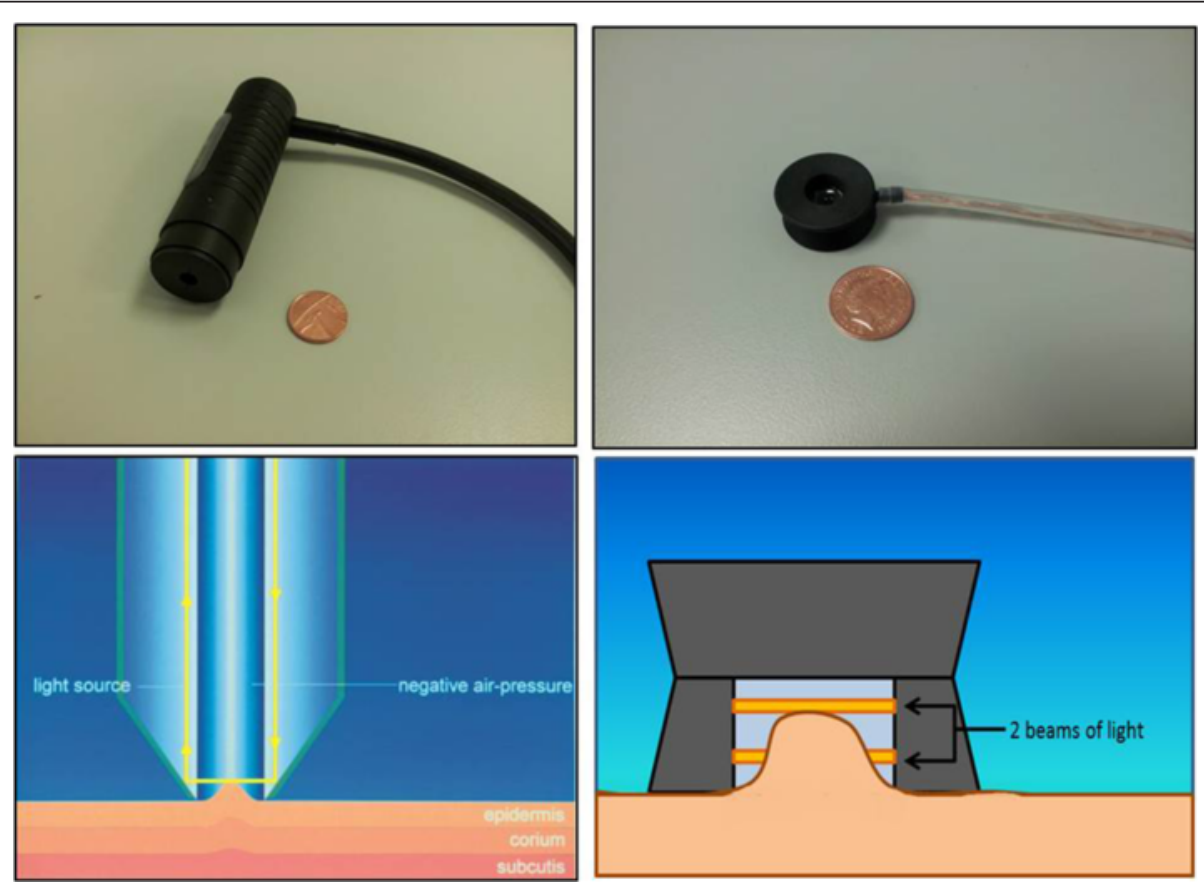

Fig. 7 The Cutometer (top left) and Dermalab elasticity probe (top right), one penny coin to provide an idea of the size of the probes. Illustration of the mechanism of the Cutometer and Dermalab elasticity probe (bottom left and right, respectively). (Source: photographs and diagram of elasticity probe by Kwang Chear Lee; Cutometer image source: Courage + Khazaka Electronic GmbH, http://www.courage-khazaka.de/index.php/ en/products/scientific/140-cutometer, reprinted with permission) 


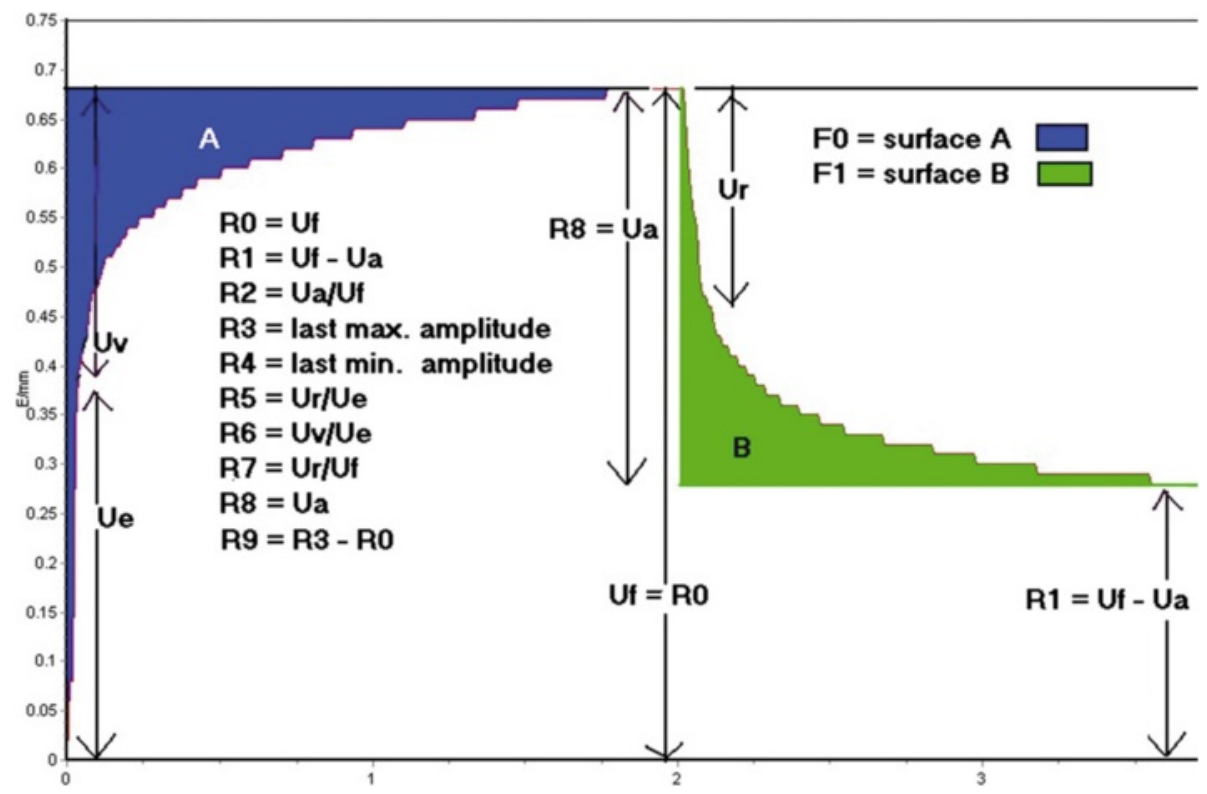

Fig. 8 Example of skin deformation curve obtained with the Cutometer. (Source: Courage + Khazaka Electronic GmbH, reprinted with permission)

of scar as they found a high correlation between the parameters $\mathrm{Ua}, \mathrm{Ue}, \mathrm{Uf}, \mathrm{Ur}$ and $\mathrm{Uv}$, and that Ue and Uf were found to have the highest reliability. Nedelec et al. agreed with this and also found Uf to have a higher reliability (but not for severe scars) but concluded that as Uf is more convenient to record (automatically calculated by computer software, whereas Ue requires manual calculations), it should be used instead.

Other studies have also utilised the $\mathrm{R}$ (dimensionless parameters derived from the $\mathrm{U}$ values) and $\mathrm{Q}$ (maximum recovery, elastic recovery and viscous recovery areas) values [143].

The Dermalab elasticity probe $[6,156]$ consists of a light plastic probe that is much smaller than that of the Cutometer (Fig. 5). This probe is attached to the skin using double-sided adhesive rings to form a closed chamber. Within this chamber, two narrow beams of light run at different heights parallel to the skin surface and serve as elevation detectors [154] (Fig. 5). A computer controlled vacuum pump connected to the probe

Table 6 Comparison of used and recommended parameters for the cutometer in different papers

\begin{tabular}{ll}
\hline Authors and papers & Parameter used/recommended \\
\hline Fong et al. 1997 [146]. & Uf, Ur/Uf, Ur/Ue, R8 \\
Draaijers et al. 2004 [147]. & Recommends Ue or Uf \\
Dobrev et al. 2005. [257] & $\begin{array}{l}\text { Recommends Ue and Uf (distensibility), } \\
\text { Ua/Uf and Ur/Uf (elasticity) and Uv and } \\
\text { Uv/Ue (viscoelasticity) }\end{array}$ \\
$\begin{array}{ll}\text { Nedelec et al. 2008 [30, 106]. } \\
\text { Rennekampff et al. 2002 [155] }\end{array}$ & Uf, Ua, Ur, Ue, Ur/Ue and Ur/Uf \\
and 2006 [142]. & \\
\hline
\end{tabular}

is then used to increase the suction within this closed chamber over 30-60 s. In contrast to the Cutometer where a set pressure is applied and the skin deformation is measured, the Dermalab elasticity probe measures the amount of suction (in kilopascals, $\mathrm{kPa}$ ) that is required to lift the skin to pass the height of the two light beams. This may cause problems when the measured skin is too stiff to be stretched enough to reach the level of the detectors [154]. The stiffness of the skin (or Young's modulus, E) is then calculated and expressed in millimeter per kilopascal. Skin that is firm, e.g. scar tissue will have a higher stiffness index compared to normal skin.

A study by Gankande et al. with the Dermalab elasticity probe showed that the test-retest reliability for pliability was "excellent" (ICC 0.76-0.91) in scar areas but only "good" (ICC 0.45, 95 \% CI 0.30-0.76) in contralateral normal skin areas [6]. It should be noted that significant difficulties were encountered by the researchers in the study in obtaining elasticity measurements and they failed to obtain matched measurements for test-retest analysis in $31-52 \%$ of the subjects [6].

Both devices have the advantage of being a "hub" to which other measuring devices can be attached. For example, the Dermalab combo device provides additional probes that can be fitted to provide spectrophotometry data (melanin and erythema) and ultrasound measurement of dermal thickness [6].

\section{Tonometry}

Tonometry measures the firmness and flexibility of skin and scars by exerting pressure either via an airflow 
system that is blocked at a certain pressure (e.g. Pneumatometer [157] (Medtronic Solan Model 30 Classic, Jacksonville, FL, USA), Cicatrometer [114], Tissue Tonometer [158] (Flinders Medical Centre Biomedical Engineering, Australia) or an indentional load in a vertical direction, e.g. durometer [114, 158-161] (Rex model H 1000, Rex Gauge company, IL, USA), Schiotz tonometer [162], and Tissue Compliance Meter [163] (Model and company not stated by author). In the study by Lye et al., the Tissue Tonometer showed good intra-observer reliability and a moderate correlation with the pliability score of the VSS scale, but the measure is a relative one as it requires a contralateral reference point [158]. A study by Corica et al. [164], utilising a modified Tissue Tonometer, showed that the intra-class correlation coefficient for averaged measures between measurers (inter-rater reliability) was 0.957 , and the standard error of measurement was $0.025 \mathrm{~mm}$. A significant difference $(p=.0000)$ between scar $(2.64 \pm 0.5 \mathrm{~mm})$ and normal tissue $(3.23 \pm 0.46 \mathrm{~mm})$ measurements was also demonstrated in the study. Tonometry devices are, however, less suitable for skin locations with hard bony structures underneath-as the hard underlying structures limit the degree in which the skin can be compressed. At the time of writing, the mechanical tonometer is no longer commercially available but a digital version is in the experimental phase. Other shortcomings with the mechanical design include the need to place the device accurately (must be within $5^{\circ}$ of upright to measure correctly).

The durometer also showed good reliability and validity in one study but this was performed on sclerodermal skin [160] which demonstrates symmetrical skin thickening compared to scars where thickening can vary from area to area depending on the initial injury.

\section{Torsional force and adherence measurement methods}

Torsional force can be used to measure the elasticity of skin (Dermal Torque Meter; Dia-Stron, UK) [165] and the device is able to differentiate between native skin, autographs and cultured skin substitutes; however, rigorous clinical appraisals of the device have not yet been performed.

\section{Acoustic methods}

The Shear Velocity Device (SVD) is a portable tool that can be used to analyse soft biologic tissue by measuring the propagation of an auditory shear wave through the skin surface $[166,167]$. The device works on the principal that an acoustic shear wave will have a higher velocity in a hard material (e.g. scar tissue) compared to softer material (e.g. normal skin). Experimental validation of the SVD by McHugh et al. claims that it provides similar results to the Shore Type A durometer; however, this data has yet to be published [166]. The coefficient of variation (CV) for the device in measurements of 254 hypertrophic scar locations was $\pm 4.8 \%$ whilst on 210 normal skin sites this was $\pm 4.4 \%$. Unfortunately, the authors have not been able to locate any subsequent publications on this device and it is not currently commercially available.

Revisometry [168] (Reviscometer; Dermaviduals and Courage + Khazaka, Germany) is another portable tool that measures the elastic and viscoelastic features of skin and scars by utilising an acoustic shock wave and reports this as resonance running time (RRT). Scars have a significantly lower mean RRT compared with normal skin (52.3 versus 91.6). It has been shown to be reliable with inter-rater observer reliability of more than 0.86 on scars but more studies are required to establish its validity and comparative performance.

\section{Electrical of bio-impedance methods}

Utilising an impedance device, the capacitance of scar tissue has been shown to be stronger than that of normal skin and the resistance of scar tissue is lower than that of normal skin. The impedance of scar tissue however varies according to the depth and density of scar tissue [132]. This electrical property of scar tissue could be utilised to quantify scars; however, no method has been developed as of yet.

\section{Modelling and other techniques}

All of the methods that have been discussed thus far rely on measurements in a small area of the scar which may not be representative of the scar as a whole.

The Adheremeter [169] (Fondazione Salvatore Maugeri, Italy) uses an entirely different approach and measures the restriction of scar mobility with respect to the underlying tissue at the worst adherent point when stretched in 4 orthogonal directions using a transparent film print-out of 9 concentric rings with varying radii. It is a relatively new device and has only been tested in one study [169] but it showed an adequate level of reliability and validity when compared to the VSS. However, it has a degree of subjectivity in operation as the measurement is based on the rater's evaluation of the force required to stretch the skin and on the patient's judgement of comfort. It is also not suitable for use on highly concave surfaces.

A different approach to measuring the elasticity of skin is to use computerised models of skin motion analysis $[170,171]$. These experimental methods are able to detect and measure the differences in elasticity between normal and scar tissue by comparing images taken at two time instances before and after deformation. Regular 2D images, combined with 3D data, can offer a method of estimating scar pliability in a more global manner [94]. In simple terms, these methods utilise a grid painted onto the skin which will then deform according to the elasticity 
of the skin. Grid portions that are less pliable (scar tissue) will deform less than areas which are more pliable (normal skin). A technique called Finite element modelling (FEM) can then be used to analyse this information [170-173]. This technique is still experimental and yet to be commercially available. Some devices that may be commercially available soon that utilise this technique include CutiScan CS 100 (Courage + Khazaka, Germany) which is still under development.

Other methods include the measurement of ranges of movement to determine the severity of burn contractures and thus indirectly the viscoelasticity of the scars. The current standard involves the measurement of the passive and active range of motion of an extremity in a single plane or functional movements (which are better related to activities of daily living) [174] using conventional measurements [175] (e.g. goniometry, tape measures, inclinometer) or 3D motion analysis [174, 176, 177]. The Faciometer (University of Vienna) measures the ranges of mimic movements, e.g. the distance between the tragus and the mouth using calipers and an electronic display [178]. A survey by Parry et al. however showed that there is a lack of consensus in the methods and tools used clinically for the measurement of burn contracture and these methods are also rarely checked for reliability or performance competency [175].

Table 7 gives a summary of the comparison of viscoelasticity devices in terms of parameter measured, reliability, correlation with clinical score and cost.

Comparing the devices that measure biomechanical properties of scars, the Cutometer seems to be the best choice at present as it is reliable (in normal, nonhypertrophic scars), shows a reasonable validity and can be used over bony areas. Additionally, the Cutometer is the most often used device for skin viscoelasticity measurements with more publications than most of the other devices reviewed in this paper.

\section{Pathophysiological disturbances}

Pathophysiological disturbances are defined as functional changes in the skin associated with, or resulting from, disease or injury, with measurable parameters including gas perfusion and moisture content.

\section{Transcutaneous oxygen tension}

Transcutaneous oxygen tension $\left(\mathrm{tcpO}_{2}\right)$ is perturbed in injured tissues and can be used as an index of maturity in hypertrophic scars. The $\mathrm{tcpO}_{2}$ in scar tissue is lower compared to healthy skin, and an increase in $\mathrm{tcpO}_{2}$ is correlated with a reduction in scar thickness assessed both clinically and by ultrasound [179]. This is thought to be due to low oxygen diffusibility through scar tissue. A study by Ichioka et al. [180] has also shown in animal and human tissues that immature repairing tissues consumed more oxygen than mature tissues and that the oxygen consumption rate in keloid and hypertrophic scars were significantly higher when compared to mature scars which may also explain the lower $\mathrm{tcpO}_{2}$ in scar tissues. The method for measuring transcutaneous oxygen tension exploits the redox reactions that occur in a modified Clark electrode that measures the oxygen $\left(\mathrm{tcpO} \mathrm{O}_{2}\right)$ and carbon dioxide $\left(\mathrm{tcpCO} \mathrm{CO}_{2}\right)$ tension on the surface of the skin. The tcpCO $\mathrm{CO}_{2}$ is considered non-specific and highly dependent of external factors, whilst the $\mathrm{tcpO}_{2}$ is a much more precise indicator of local perfusion [181]. This technique seems to have been recently abandoned from clinical practice.

\section{Transepidermal water loss and moisture content}

The water content of the skin is an important factor that influences the softness and smoothness of the skin, and transepidermal water loss and skin hydration are key indicators of skin function. Transepidermal water loss (TEWL) and moisture content can be measured by open and closed chamber systems. Open systems such as the Dermalab TEWL module [182] and Tewameter [183] (Courage + Khazaka, Germany) are the most frequently used (Fig 9). Closed systems such as the Vapometer (Delphin Technologies, Finland) are also available, but one study has shown that the Tewameter is able to detect significantly smaller differences in TEWL when compared to the Vapometer [184]. Anthonissen et al. showed a significant difference in mean TEWL values between normal skin and spontaneously healed scars $(p=0.036)$ and a significant negative relation between mean TEWL values and time after burn $(p=0.008)$; however, high SEM values were reported $[156,185]$.

The hydration of the skin layers, specifically the stratum corneum, can also be measured using electrical methods, such as the conductance method (for example, the Skicon-200 conductance meter [186, 187], IBS Co, Hamamatsu, Japan, Location, and the NOVA Dermal phase Meter [188], Nova, Technology Corp., Gloucester, Mass.) and impedance method (for example, the Corneometer [186], Courage + Khazaka, Germany). One study has shown that the Corneometer is suitable for use in clinical trials, with useful intra-class correlation coefficient $($ ICC) values (ICCintra $=0.985$; ICCinter $=0.984$ ), but only under very strict conditions with a standardised test protocol [189]. Another method for measuring hydration (and protein content) is to measure the dielectric properties of the skin. This is based on the interaction of high-frequency electromagnetic (EM) waves and biological material [190, 191]. The EM waves are generated using a network analyser (HP8753B, Agilent, USA).

A study by Suetake et al. found that TEWL was a better parameter for the functional evaluation of scars than 
Table 7 Comparison of viscoelasticity devices in terms of parameter measured, reliability, correlation with clinical score and cost

\begin{tabular}{|c|c|c|c|c|c|c|c|c|}
\hline Device & Company & Parameter & Intra-rater Reliability & Inter-rater reliability & Correlation with clinical score & Cost & Portability & References \\
\hline Cutometer & Courage + Khazaka & $\begin{array}{l}\text { Viscoelastic } \\
\text { parameters }\end{array}$ & $\begin{array}{l}\text { Ranges from } \\
\text { unacceptable to } \\
\text { good }(0.12-0.76)^{*} ; \\
\text { poor in severe firm } \\
\text { scars }\end{array}$ & $\begin{array}{l}\text { Ranges from } \\
\text { unacceptable to } \\
\text { good }(0.11-0.93)^{*}, \\
\text { poor in severe } \\
\text { firm scars }\end{array}$ & $\begin{array}{l}\text { Low to moderate, but } \\
\text { significant (Spearman's } \\
r=-0.29 \text { to }-0.53 \text { ). } \\
\text { Rennekampf et al. could } \\
\text { not find any significant } \\
\text { correlation between } \\
\text { objective viscoelastic } \\
\text { measurements and the } \\
\text { subjective pliability } \\
\text { assessment of the VSS. }\end{array}$ & $\begin{array}{l}£ 5000-£ 10,000 \\
\text { (with hub) }\end{array}$ & Yes & $\begin{array}{l}\text { Nedelec et al. } 2008 \text { [30, 106], } \\
\text { Draaijers et al. } 2004 \text { [147], } \\
\text { Rennekampf et al. } 2006 \text { [142]. }\end{array}$ \\
\hline $\begin{array}{l}\text { Dermalab } \\
\text { Elasticity } \\
\text { probe }\end{array}$ & Cortex & $\begin{array}{l}\text { Viscoelastic } \\
\text { parameters }\end{array}$ & $\begin{array}{l}\text { ICC }=0.90-0.93 \\
\text { limited ability to } \\
\text { measure rigid scars }\end{array}$ & $\begin{array}{l}\text { ICC }=0.86-0.93 ; \\
\text { limited ability to } \\
\text { measure rigid } \\
\text { scars }\end{array}$ & No data & $\begin{array}{l}£ 5000-£ 10,000 \\
\text { (with hub) }\end{array}$ & Yes & Gankande et al. 2014 [6]. \\
\hline Tonometer & $\begin{array}{l}\text { Flinders Medical } \\
\text { Centre Biomedical } \\
\text { Engineering }\end{array}$ & $\begin{array}{l}\text { Viscoelastic } \\
\text { parameters }\end{array}$ & ICC $=0.90-0.94$ & $\mathrm{ICC}=0.948$ & $\begin{array}{l}\text { Negative correlation } \\
\text { between VSS } \\
\text { pliability scores and } \\
\text { tonometer readings: } \\
-0.457 \text { and }-0.442 \\
\text { respectively for } 3 \text { and } \\
6 \text { second readings. }\end{array}$ & $\begin{array}{l}\text { No longer } \\
\text { commercially } \\
\text { available }\end{array}$ & Yes & $\begin{array}{l}\text { Corica et al. } 2006 \text { [164], } \\
\text { Lye et al. } 2006 \text { [158]. }\end{array}$ \\
\hline Durometer & Rex Gauge company & $\begin{array}{l}\text { Viscoelastic } \\
\text { parameters }\end{array}$ & No data & $\begin{array}{l}\text { No data for scars } \\
\text { but ICC }=0.82-0.92 \\
\text { for sclerodermal } \\
\text { skin }\end{array}$ & $\begin{array}{l}\text { Good correlation with } \\
\text { modified Rodnan skin } \\
\text { score }(0.70) \text { for } \\
\text { sclerodermal skin }\end{array}$ & $<£ 1000$ & Yes & Merkel et al. 2008 [160]. \\
\hline $\begin{array}{l}\text { Dermal Torque } \\
\text { meter }\end{array}$ & Dias-tron & $\begin{array}{l}\text { Viscoelastic } \\
\text { parameters }\end{array}$ & No data & No data & No data & $\mathrm{N} / \mathrm{a}$ & Yes & Boyce et al. 2000 [165]. \\
\hline Adheremeter & $\begin{array}{l}\text { Fondazione } \\
\text { Salvatore Maugeri }\end{array}$ & $\begin{array}{l}\text { Viscoelastic } \\
\text { parameters }\end{array}$ & Good (0.96) & Good (0.87-0.99) & $\begin{array}{l}\text { Moderate correlation } \\
\text { with VSS and Pliability } \\
\text { subscale of VSS } \\
\text { (rs }=-0.58 \text { to }-0.66)\end{array}$ & Free & Yes & Ferriero et al. 2010 [169]. \\
\hline Reviscometer & Courage + Khazaka & $\begin{array}{l}\text { Resonance } \\
\text { running time }\end{array}$ & Good (>0.86) & No data & No data & $\begin{array}{l}£ 10,000-15,000 \\
\text { (with hub) }\end{array}$ & Yes & Verhaegen et al. 2010 [168]. \\
\hline Vesmeter & Wave Cyber Co. Ltd. & No data & No data & No data & No data & $\mathrm{N} / \mathrm{a}$ & Yes & Niyaz et al. 2012 [246]. \\
\hline $\begin{array}{l}\text { Shear Velocity } \\
\text { Device }\end{array}$ & $\mathrm{N} / \mathrm{a}$ & $\begin{array}{l}\text { Shear wave } \\
\text { propagation } \\
\text { velocity }\end{array}$ & $\begin{array}{l}\text { No data for ICC. } \\
\text { (CV for scars } \\
\text { is } \pm 4.8 \% \text { ) }\end{array}$ & No data & No data & $\begin{array}{l}\text { Not commercially } \\
\text { available }\end{array}$ & Yes & McHugh et al. 1997 [166]. \\
\hline
\end{tabular}

*Low ICC values for Cutometer may also be attributed to the difficulty in relocating device to same measurement spot and the high sensitivity of the device [30]

$I C C=$ intra-class correlation coefficients; $C V=$ coefficient of variation; VSS = Vancouver Scar Scale 


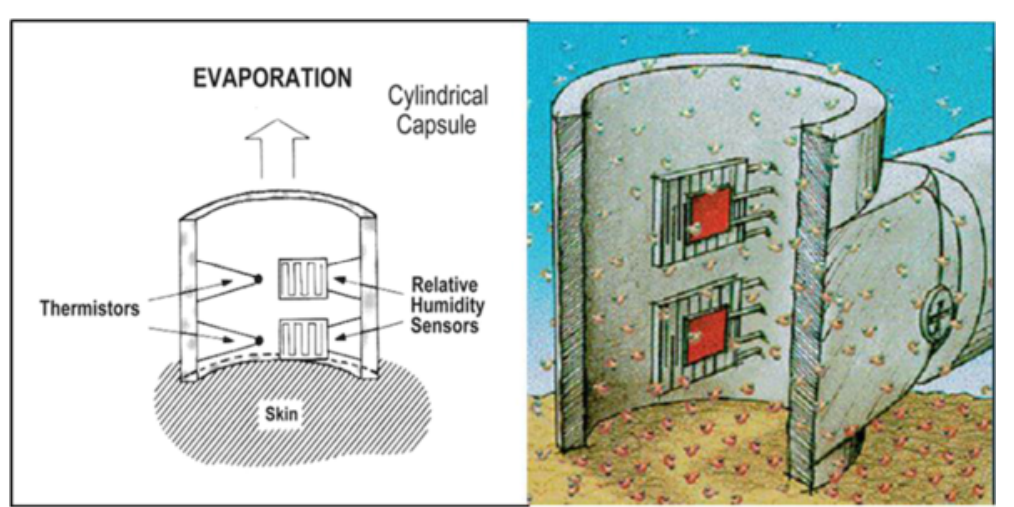

Fig. 9 Open chamber transepidermal water loss system. (Source: Courage + Khazaka Electronic GmbH and Cortex Technology, reprinted with permission)

was the hydration state of the skin surface measured by high-frequency conductometry [192].

\section{Multispectral imaging systems}

A novel polarised multispectral imaging system that combines out-of-plane Stokes polarimetry and Spatial Frequency Domain Imaging has been developed by Ghassemi et al. and allows the colour (haemoglobin, melanin), pathophysiology (blood oxygenation, hydration) as well as structural features (cellularity and roughness) of hypertrophic scars to be analysed in vivo [193, 194]. The results obtained with this multi-modal system showed a good agreement with the VSS and with histological examinations [193]. Although still in experimental stages, it could potentially simplify the scar measuring process due to its multi-modal measurements.

\section{Non-invasive morphological imaging techniques}

Previously, histopathological analysis of biopsy samples was the only method of morphological investigation of damaged biological tissues. Now, recent advances in imaging techniques have made non-invasive in vivo morphological investigation of tissue microstructure possible.

\section{Optical coherence tomography}

With the advances in fibre optics and other technologies such as ultra-broadband light sources and frequency domain techniques, optical coherence tomography (OCT) imaging that is capable of generating 3D images of tissue microstructure is now possible. OCT is most frequently used in ophthalmology [195] but can be adapted to be used to analyse the skin [196-203]. OCT can be utilised in various different modes for the assessment of scars $[202,203]$. The layered arrangement of normal skin is perturbed in scarred skin so that OCT can be used to provide information about microstructure as well as depth and volume [196]. Scar tissue imaged by OCT appears dense and bright due to the increased collagen content, and this parameter can be used to measure the collagen status of scars [204]. Scar microvasculature density has been quantified using an automated OCT system and found to be increased in hypertrophic scar tissues (38 \%) when compared against normal, unscarred skin (22\%) [201]. Vessels in scars have also been shown to be much larger compared to normal skin on OCT [205]. However, due to the strong scattering and absorption of light by skin, current OCT methods are only capable of imaging to a depth of 1 to $2 \mathrm{~mm}$, whereas scar thickness is usually greater than $2 \mathrm{~mm}$ (as determined by ultrasound) $[6,103$, 206]. Nevertheless, in areas where scar tissue is thinner (e.g. in fingers), OCT (utilising the 1300-nm wavelength region) may still be useful [196]. Another way of differentiating scar tissue from normal tissue using OCT is the use of the attenuation rate, which is defined as the rate at which the OCT signal decreases with depth in the tissue [203]. Lower attenuation coefficients are seen in scarred tissue compared with normal skin tissue [203]. This method bypasses the problem of penetration depth but yields less detailed morphological data when compared to standard OCT methods. A form of OCT (termed "Polarization-sensitive Optical Frequency Domain Imaging") can also be used to image collagen remodelling [207].

OCT imaging has been demonstrated to be feasible for use in the clinical monitoring of scar progression automated quantification of vascularity in cutaneous burn scars [195]. OCT imaging for scarring and fibrosis is currently still in its infancy and further development in the technology is required. In a study by Eraud et al. [208], although OCT was able to detect dermal nodules (which are present in hypertrophic but not keloid scars [209]) in $100 \%$ of the specimens, it was not helpful in identifying hyalinised collagen (which is present in keloids) and cells. The technology however has the potential for tremendous growth [204]. 


\section{Other in vivo tomography/microscopy techniques}

Imaging techniques utilising specialised optical microscopes have been used to image scar tissue.

Nonlinear spectral imaging, such as multi-photon tomography based on both two-photon excited fluorescence (TPEF) and second harmonic generation (SHG), can be utilised to demonstrate the morphological structure and spectral characteristics of collagen (with SHG) and elastin fibres (with TPEF) and thus can be used to potentially distinguish hypertrophic scar tissues from normal skin and to evaluate the effects of treatments [210-216]. Information on the orientation of collagen fibres can also be investigated and analysed from these images using fast Fourier transform methods [217, 218]. Advantages these techniques have are that several extracellular matrix components and endogenous biomolecules such as collagen, keratin, melanin and elastin can be visualised in living tissue without the need for specialised processing or staining [219, 220] and high-resolution, high-contrast three-dimensional images can be obtained [220, 221].

These techniques however have similar drawbacks to OCT. The maximum depth of two-photon imaging has been reported to reach up to $1 \mathrm{~mm}$ in living brains [222] and thus is comparable to OCT imaging but clinical use in the skin is typically only up to $200 \mu \mathrm{m}$, thereby limiting its potential utility for deep scar assessment. In addition, advances in the miniaturisation of spectral imaging apparatus need to be made before it can become of practical use in a clinical setting. The multi-photon technique also has high overall system costs, a long measurement times and the inability to quantify skin redness [223]. Other non-invasive in vivo imaging techniques which currently being developed, such as confocal laser microscopy (CLM) [224, 225], also have a limited imaging depth $(\sim 300 \mu \mathrm{m})$ due to tissue-related aberrations and light scattering [226].

Other similar microscopy techniques include phasecontrast microtomography with synchrotron radiation technology to detect the 3D structure of dermal tissues [221].

\section{Spectroscopy techniques}

Another imaging method that holds future promise is the use of optical spectroscopy methods in the UVvisible-near-infrared wavelength range, including diffuse reflectance (DR) and autofluorescence (AF) spectroscopies. DR spectroscopy is based on the scattering of photons $(350-800 \mathrm{~nm})$ inside biological tissues due to the differences in the refractive indices and morphology of the constituents of skin such as collagen fibres. AF spectroscopy, on the other hand, is based on the fluorescence emissions from endogenous fluorophores such as collagen and elastin when excited by light in the 350-459 nm wavelength range. A combination of both spectroscopy methods increases its accuracy [227] and has been used successfully in a rabbit hypertrophic scar model with high sensitivity and specificity [228, 229]. DR spectroscopy on its own has also been shown to be able to differentiate keloids from normal skin in terms of collagen concentration, haemoglobin oxygen saturation and scattering coefficient in an in vivo human study [217] and can potentially be used to evaluate keloid scar severity [230].

\section{High-frequency ultrasound systems}

High-frequency ultrasound systems (such as the Dermascan and Dermalab systems [6], Cortex, Denmark) are able to provide a much greater depth of imaging $(\sim 8 \mathrm{~mm}$ at $20 \mathrm{MHz})$ but the resolution is inferior to OCT, CLM and MPT [196]. Pathological scars appear as easily identified echo-poor areas that are clearly distinguishable from normal skin and with densitometry analysis with dedicated software, scars are also shown to have significantly reduced densitometric values compared with normal skin (7.6 \pm 4.7 versus $31.79 \pm 10.8$ ) [231]. More detailed architectural information such as collagen arrangement and cell structure cannot currently be visualised with 2D nor 3D ultrasound techniques.

\section{Intravital video-capillaroscopy}

Intravital video-capillaroscopy [232] is a technique that utilises an optic contact probe microscope that is attached to a computerised video microscope (e.g. Microwatcher Model VS-901, Mitsubishi Kasei Corp, Tokyo, Japan [232]) which allows photographic images of skin capillaries to be taken. Scarred skin has a deranged capillary organisation. The pictures are then scored either subjectively and/or objectively. Subjective methods score images according to angiogenic markers [232, 233] such as enlarged or tortuous loops, architectural derangement, neoangiogenesis and quantitative changes of capillary lesions. These scoring systems can be modified to allow objective quantification [234, 235]; for example, the methods used in a study by Hern et al. allowed for both non-stereological measurements (microvessel density and vessel image width) and stereological measurements (image area fraction and microvessel length density) [235]. Intravital capillaroscopic measurement of capillary density (CD) has been shown to be reliable and reproducible with a mean coefficient of intra-observer variation of $\mathrm{CD}$ estimate of $5.6 \%$ and the inter-observer correlation coefficient of 0.94 [236].

A similar technique, dermoscopy, and its use in the examination of vascular structures can be a clinically 
useful diagnostic tool for differentiating between keloids and hypertrophic scars [237].

The dermoscopy can be used to visualise capillaries and pigmentation in the epidermal and dermal layers of the skin. An added advantage is that since dermascopes have their own light source, it is not likely to be affected by differences in environmental lighting which has been shown by Wei et al [238].

Wei et al. [238] showed that the $\mathrm{L}^{*}$ (or lightness reading) from the Dermoscope (Hong Kong Productivity Council) had a significant correlation $(0.448-0.536, p<0.01)$ with the readings from the MiniScan XE Plus spectrocolorimeter (HunterLab, Reston, VA, USA) and VSS scores of pigmentation (when the skin was blanched with pressure; $r=0.783, p<0.01)$. The RGB values of redness also showed a strong correlation with the VSS scores of vascularity $(r=0.625, p<0.01)$. Both the intra-rater and inter-rater reliability of the dermoscope were found to be excellent (0.965-0.98 and 0.871 to 0.930 , respectively).

\section{Measurement of sensory change}

A majority of patients with burn scars experience a change in sensation of the scarred skin such as pruritis, pain and hyper- or hypo-sensitivity is common in scars and this can often last for years after the initial injury [239]. However, the objective measurement of such sensory deficits is challenging task and the only gold standard for pain assessment available currently is self-report.

Functional MRI (fMRI) scans have shown promise in assessing pain in the absence of self-report however it is far from ready for regular clinical use [240]. However, skin sensitivity/touch and (indirectly) pain can be examined in an objective manner with the touch pressure threshold method (TPT) using for example Semmes Weinstein monofilaments, which have been shown to have good intra- and inter-rater reliability $(\mathrm{ICC}=0.822$ and 0.908 , respectively) in patients with scars [241].

More recently, an electronic version of the von Frey filaments is also available and showed better reproducibility compared to the traditional von Frey with good to almost perfect intra-observer reliability (ICC ranges from 0.61 to $>0.8$ ) (study done on normal skin, not scars) $[242,243]$.

\section{Discussion}

There have been significant advances in many aspects of burn treatment, but hypertrophic scarring remains as one of the major chronic problems after severe burns with few therapeutic options currently available. The accurate assessment of scarring is an important aspect of research into better treatments for this condition. Despite this, scar assessment is still mostly subjective and there is still little consensus regarding the ideal scar measurement tool [244].
Most if not all currently used subjective scales used in evaluating skin scars assume that scar dimensions conform to linear models and thus employ equal appearing interval (EAI) scales. However, a study by Brandt et al. showed that whilst pliability, thickness and surface area were defined well using linear models, the dimensions of vascularity and pigmentation were more accurately described using curvilinear functions [245].

Tools for scar measurement are often modified from tools developed for other industries, e.g. dermatological use in the cosmetic industry, such as the Cutometer; colour probes for measuring the colours of materials in the food and building industries and durometers such as the Vesmeter for testing the hardness of materials in the manufacturing industry [246]. As such, their utility for burns patients is mostly unproven. Accordingly, trials on these tools to evaluate their accuracy and reliability are scarce and few trials have compared the different devices.

The ideal assessment of scars should include the objective and subjective aspects of scars as well as an assessment of the functional limitations that are caused by the scar tissues [94]. The different physical aspects of scars can all change independently of each other during the course of scar evolution and as such a hybrid method of scar assessment which incorporates the most reliable and feasible methods should be used [247]. Combination systems such as the Dermalab combo which incorporate multiple scar measurement tools (e.g. colour, thickness and pliability $[6,248]$ ) are now available [248] to facilitate this although improvement in the clinical interpretation of the measurements is required [247].

A problem with validating objective scar measurement tools is the lack of an ideal gold standard.

Biopsies and standard histological analysis whilst proven to be accurate mostly rely on subjective scoring systems [249] unless quantitative measurement techniques are used [43]. Furthermore, Singer et al. showed that histomorphologic scales have been shown to only correlate fairly with gross macroscopic scores [249]. Beausang et al. also found that the clinical scar appearance correlated better with the upper portion of the skin (epidermis and papillary dermis) compared to the deeper parts of the scar [43]. Therefore, the lack of correlation of objective measurement techniques with clinical subjective scores should be considered carefully and not used to dismiss the objective methods.

Future validation studies of pigmentation and vascularity may be possible with standard colour reference cards developed for the cosmetic industry [250].

Objective scar measurement tools are important, especially for interventional clinical studies, as scars and the effect of therapies can be described, analysed and compared more accurately than is possible with 
subjective scar scales. Subjective scar scales however should still be incorporated into studies as they can provide a more global assessment of the scar and allow the measurement of variables that are currently not possible with objective measurement devices, such as pain and itch. Indeed, several published studies have incorporated both subjective and objective scar measuring tools $[251,252]$.

The implementation of objective measurement devices into standard clinical practice still faces many obstacles and there are multiple reasons why potentially great technologies are struggling to get incorporated into the health care system.

As mentioned previously, many new technologies (including all if not most of the devices mentioned in this review) have been developed for non-medical uses and very little if any input has been sought from clinicians or patients during the design process, and thus these devices may have limited practical clinical use. The lack of data security features is also a factor although this issue probably applies more to mobile apps rather than physical devices.

Some clinicians also view the use of new technologies in clinical practice as a crutch to the development of clinical acumen even though many studies have shown that clinical judgement to perform poorer, e.g. in determining surface area [253] or burn depth [254].

Another main issue is the high cost of these devices. Even the simplest of devices, e.g. colour probe, costs at least $>£ 3000$ not including annual servicing costs. Without solid research evidence of clinical and patient benefit, it is difficult to justify the costs and use of these devices outside of research.

Despite many of these devices being fairly simple to use, a certain level of technical expertise and additional clinical time to collect and analyse the data generated is still required. To take an example, electronic health records have been used more frequently in hospitals nowadays but it takes longer for an average clinician to input data into the electronic system than onto a paper record for months, even years, after they have started using them [255]. This has been anecdotally quoted as one of the main reasons why some burn clinicians have been slow to adopt new technologies such as LDI in determining burn depth even though there is strong evidence for its accuracy compared to clinical judgement. Staff specially trained in the use of these devices and who are responsible for training of other staff and championing their use in regular clinical practice may be the way forward [255].

Lastly, the scope of this review largely did not include journals or articles in physical sciences or engineering which may have unearthed more potentially useful objective scar measurement devices.

\section{Conclusions}

In this review, we aimed to recommend a panel of objective scar measurement tools for burn scars to be used in conjunction with subjective scar scales, that were reliable, patient friendly, and easy to use (feasibility in terms of cost and portability have now been commented on in the tables in the various sections); generated simple data; and were appropriate for use in a clinical (bedside) environment (i.e. portable). We included in the panel the least number of devices that could measure surface area, colour, thickness, pliability, texture or topography and pathophysiological skin disturbances in order to reduce measurement time and cost. All of the devices considered for inclusion have to be commercially available. As such, the recommended device panel for burn scar assessment is as follows:

- 3D wound measurement camera systems (Eykonal Lifeviz/Vectra H1): for surface area, texture, volume (including clinical thickness) and colour.

- Dermascan: for histological thickness measurements (the TUPS is an alternative but not commercially available).

- DSM II Colormeter: for colour measurements (both Tristimulus reflectance colorimetry and narrow-band simple spectrophotometry).

- Cutometer system: for viscoelastic measurements of the skin.

- Tewameter (optional probe for the Cutometer system): for the measurement of transepidermal water loss.

Further studies are needed to validate the performance and utility of this scar panel and to compare them with the commonly used subjective scar scales, such as the POSAS.

It is recommended that new technologies to be utilised in objective measurement should ideally be evaluated in terms of intra- and inter-rater reliability (with at least two observers) before being used in trials; however, this could be time and resource consuming. Collaborations should be established between the industry, clinical research and patient groups to streamline and refine this process and encourage the testing and introduction of improved devices.

Although there is a greater emphasis now compared to previous decades on developing and evaluating devices that measure physical scar parameters, scarce attention has been given to measure the physiological characteristics of scars. It is essential to develop tools that can be used to measure and quantify metabolic and cellular activity in scars so that treatments can be tailored to the individual. 


\section{Competing interests}

The authors declare that they have no competing interests.

\section{Authors' contributions}

$\mathrm{KL}$ conceived and designed the review, collected the data (including searches, screening and extracting data from the papers) and wrote the manuscript. $K L$ and JD designed the search methodology. $L G$, AL and NM provided general advice on the review and reviewed the manuscript drafts before submission. All authors read and approved the final manuscript.

\section{Author details}

'The Healing Foundation Burn Research Centre, University Hospital Birmingham Foundation Trust, Birmingham B15 2TH, UK. ${ }^{2}$ Public Health, Epidemiology and Biostatistics, Institute of Applied Health Research, College of Medical and Dental Sciences, University of Birmingham, Birmingham B15 $2 \pi$, UK. ${ }^{3}$ School of Chemical Engineering, University of Birmingham, Birmingham B15 2TT, UK. ${ }^{4}$ School of Clinical and Experimental Medicine, College of Medical and Dental Sciences, University of Birmingham, Birmingham B15 2TT, UK.

\section{Received: 14 January 2016 Accepted: 29 March 2016} Published online: 27 April 2016

\section{References}

1. World Health Organisation. Disease and injury regional estimates, 20042008. [19th Apr 2016] Available from: http://www.who.int/healthinfo/global_ burden_disease/estimates_regional_2004_2008/en/

2. Global Health Estimates: deaths, disability-adjusted life year (DALYs), years of life lost (YLL) and years lost due to disability (YLD) by cause, age and sex, 2000-2012. Geneva: World Health Organization. [29 Feb 2016]. Available from: http://www.who.int/healthinfo/global_burden_disease/estimates/en/.

3. Brusselaers N, Hoste EA, Monstrey S, Colpaert KE, De Waele JJ, Vandewoude $\mathrm{KH}$, et al. Outcome and changes over time in survival following severe burns from 1985 to 2004. Intensive Care Med. 2005;31(12):1648-53.

4. Draaijers $\sqcup$, Tempelman FR, Botman YA, Tuinebreijer WE, Middelkoop E, Kreis RW, et al. The patient and observer scar assessment scale: a reliable and feasible tool for scar evaluation. Plast Reconstr Surg. 2004;113(7):1960-5. discussion 6-7.

5. Brusselaers N, Pirayesh A, Hoeksema H, Verbelen J, Blot S, Monstrey S. Burn scar assessment: a systematic review of different scar scales. The Journal of surgical research. 2010;164(1):e115-23.

6. Gankande TU, Duke JM, Danielsen PL, DeJong HM, Wood FM, Wallace HJ. Reliability of scar assessments performed with an integrated skin testing device - The DermaLab Combo((R)). Burns : journal of the International Society for Burn Injuries. 2014;40(8):1521-9.

7. Kaartinen IS, Valisuo PO, Alander JT, Kuokkanen HO. Objective scar assessmenta new method using standardized digital imaging and spectral modelling. Burns : journal of the International Society for Burn Injuries. 2011;37(1):74-81.

8. Kaartinen IS, Valisuo PO, Bochko V, Alander JT, Kuokkanen HO. How to assess scar hypertrophy-a comparison of subjective scales and Spectrocutometry: a new objective method. Wound repair and regeneration : official publication of the Wound Healing Society [and] the European Tissue Repair. Society. 2011;19(3):316-23.

9. Hoogewerf CJ, van Baar ME, Middelkoop E, van Loey NE. Impact of facial burns: Relationship between depressive symptoms, self-esteem and scar severity. Gen Hosp Psychiatry. 2014;36(3):271-6.

10. Landis JR, Koch GG. The measurement of observer agreement for categorical data. Biometrics. 1977;33(1):159-74

11. Alster TS, Lewis $A B$, Rosenbach A, et al. Laser scar revision: comparison of $\mathrm{CO} 2$ laser vaporization with and without simultaneous pulsed dye laser treatment. Dermatologic surgery : official publication for American Society for Dermatologic Surgery. 1998;24(12):1299-302.

12. Winkler AD, Spillmann L, Werner JS, Webster MA. Asymmetries in blue-yellow color perception and in the color of 'the dress'. Current biology: CB. 2015.

13. Tseng FY, Chao CJ, Feng WY, Hwang SL. Assessment of human color discrimination based on illuminant color, ambient illumination and screen background color for visual display terminal workers. Ind Health. 2010;48(4): 438-46.

14. Shuwairi SM, Cronin-Golomb A, McCarley RW, O'Donnell BF. Color discrimination in schizophrenia. Schizophr Res. 2002;55(1-2):197-204.
15. Draaijers L, Tempelman FR, Botman YA, Kreis RW, Middelkoop E, van Zuijlen PP. Colour evaluation in scars: tristimulus colorimeter, narrow-band simple reflectance meter or subjective evaluation? Burns : journal of the International Society for Burn Injuries. 2004;30(2):103-7.

16. Davey RB, Sprod RT, Neild TO. Computerised colour: a technique for the assessment of burn scar hypertrophy. A preliminary report. Burns : journal of the International Society for Burn Injuries. 1999;25(3):207-13.

17. Li-Tsang CW, Lau JC, Liu SK. Validation of an objective scar pigmentation measurement by using a spectrocolorimeter. Burns : journal of the International Society for Burn Injuries. 2003;29(8):779-84.

18. Chan HH, Wong DS, Ho WS, Lam LK, Wei W, et al. The use of pulsed dye laser for the prevention and treatment of hypertrophic scars in chinese persons. Dermatologic surgery : official publication for American Society for Dermatologic Surgery. 2004;30(7):987-94. discussion 94.

19. Kim MS, Rodney WN, Cooper T, Kite C, Reece GP, Markey MK. Towards quantifying the aesthetic outcomes of breast cancer treatment: comparison of clinical photography and colorimetry. J Eval Clin Pract. 2009;15(1):20-31.

20. van der Wal M, Bloemen $M$, Verhaegen $P$, Tuinebreijer W, de Vet $H$, van Zuijlen $P$, et al. Objective color measurements: clinimetric performance of three devices on normal skin and scar tissue. Journal of burn care \& research : official publication of the American Burn Association. 2013;34(3):e187-94.

21. Akita S, Akino K, Imaizumi T, Hirano A. A basic fibroblast growth factor improved the quality of skin grafting in burn patients. Burns : journal of the International Society for Burn Injuries. 2005;31(7):855-8.

22. Ardigò M, Muzio F, Picardo M, Brazzelli V. In: Picardo M, Taïeb A, editors. Non-invasive methods for vitiligo evaluation. London, New York: Springer Heidelberg Dordrecht; 2010.

23. Yip C. Re-pigmentation of skin following wounding. Manchester, UK: The University of Manchester; 2013.

24. Barel AO, Clarys P, Alewaeters K, Duez C, Hubinon JL, Mommaerts M. The Visi-Chroma VC-100: a new imaging colorimeter for dermatocosmetic research. Skin research and technology : official journal of International Society for Bioengineering and the Skin (ISBS) [and] International Society for Digital Imaging of Skin (ISDIS) [and] International Society for Skin Imaging (ISSI). 2001;7(1):24-31.

25. Hallam MJ, McNaught K, Thomas AN, Nduka C. A practical and objective approach to scar colour assessment. Journal of plastic, reconstructive \& aesthetic surgery : JPRAS. 2013;66(10):e271-6.

26. van der Wal MB, van Zuijlen PP, van de Ven P, Middelkoop E. Topical silicone gel versus placebo in promoting the maturation of burn scars: a randomized controlled trial. Plast Reconstr Surg. 2010;126(2):524-31.

27. Verhaegen PD, Bloemen MC, van der Wal MB, Vloemans AF, Tempelman FR, Beerthuizen $\mathrm{Gl}$, et al. Skin stretching for primary closure of acute burn wounds. Burns: journal of the International Society for Burn Injuries. 2014; 40(8):1727-37.

28. Nedelec B, Correa JA, de Oliveira A, LaSalle L, Perrault I. Longitudinal burn scar quantification. Burns : journal of the International Society for Burn Injuries. 2014;40(8):1504-12.

29. Oliveira GV, Chinkes D, Mitchell C, Oliveras G, Hawkins HK, Herndon DN, et al. Objective assessment of burn scar vascularity, erythema, pliability, thickness, and planimetry. Dermatologic surgery : official publication for American Society for Dermatologic Surgery. 2005;31(1):48-58.

30. Nedelec B, Correa JA, Rachelska G, Armour A, LaSalle L. Quantitative measurement of hypertrophic scar: intrarater reliability, sensitivity, and specificity. Journal of burn care \& research : official publication of the American Burn Association. 2008;29(3):489-500.

31. Cheon $Y$, Lee $W$, Rah D. Objective analysis of burn scar color by $L^{*} a^{*} b^{*}$ color coordinates. Burns : journal of the International Society for Burn Injuries. 2009;35:S33.

32. Cheon YW, Lee WJ, Rah DK. Objective and quantitative evaluation of scar color using the $L^{*} a^{*} b^{*}$ color coordinates. The Journal of craniofacial surgery. 2010;21(3):679-84

33. Valisuo P, Harju T, Alander J. Reflectance measurement using digital camera and a protecting dome with built in light source. J Biophotonics. 2011;4(7-8):559-64.

34. Bae EJ, Seo SH, Kye YC, Ahn HH. A quantitative assessment of the human skin surface using polarized light digital photography and its dermatologic significance. Skin research and technology : official journal of International Society for Bioengineering and the Skin (ISBS) [and] International Society for Digital Imaging of Skin (ISDIS) [and] International Society for Skin Imaging (ISSI). 2010;16(3):270-4 
35. Khorasani H, Zheng Z, Nguyen C, Zara J, Zhang X, Wang J, et al. A quantitative approach to scar analysis. Am J Pathol. 2011;178(2):621-8

36. Ferreira T, Rasband W. ImageJ User Guide — IJ 1.46 2010-2012 [2nd September 2015]. imagej.nih.gov/ij/docs/guide/]

37. Burke-Smith A, Collier J, Jones I. A comparison of non-invasive imaging modalities: Infrared thermography, spectrophotometric intracutaneous analysis and laser Doppler imaging for the assessment of adult burns. Burns journal of the International Society for Burn Injuries. 2015.

38. Jones HG. Clinimetrics of tristimulus colourimeters in scar assessment: a review of evidence. J Wound Care. 2012;21(1):30-5.

39. Moncrieff M, Cotton S, Claridge E, Hall P. Spectrophotometric intracutaneous analysis: a new technique for imaging pigmented skin lesions. The British journal of dermatology. 2002;146(3):448-57.

40. Ud-Din S, Perry D, Giddings P, Colthurst J, Zaman K, Cotton S, et al. Electrical stimulation increases blood flow and haemoglobin levels in acute cutaneous wounds without affecting wound closure time: Evidenced by non-invasive assessment of temporal biopsy wounds in human volunteers. Exp Dermatol. 2012;21(10):758-64.

41. Li ZY, Su HT, Lu SL, Huang LB, Yang XB, Shao TB, et al. [Clinical study on the relationship among the dermis, fat dome and postburn hyperplastic scar formation]. Zhonghua shao shang za zhi $=$ Zhonghua shaoshang zazhi $=$. Chinese journal of burns. 2004;20(6):343-6.

42. Wan BK, Qi HZ, Ming D, Zhang MJ, Wang QF. Chromatic analysis of burn scar based on ANN by using photoelectrical technology. In: Chance B, Chen M, Chiou AET, Luo Q, editors. Optics in Health Care and Biomedical Optics: Diagnostics and Treatment li, Pts 1 and 2. Proceedings of the Society of Photo-Optical Instrumentation Engineers (Spie). 56302005. 538-43.

43. Beausang $\mathrm{E}$, Floyd $\mathrm{H}$, Dunn KW, Orton $\mathrm{Cl}$, Ferguson MW. A new quantitative scale for clinical scar assessment. Plast Reconstr Surg. 1998;102(6):1954-61.

44. Powell MW, Sarkar S, Goldgof DB, Ivanov K. A methodology for extracting objective color from images. IEEE transactions on systems, man, and cybernetics Part B, Cybernetics : a publication of the IEEE Systems, Man, and Cybernetics Society. 2004;34(5):1964-78.

45. Anderson JC, Hallam MJ, Nduka C, Osorio D. The challenge of objective scar colour assessment in a clinical setting: using digital photography. J Wound Care. 2015;24(8):379-87.

46. van Zuijlen PP, Angeles AP, Kreis RW, Bos KE, Middelkoop E. Scar assessment tools: implications for current research. Plast Reconstr Surg. 2002;109(3): 1108-22.

47. Valente JH, Jay GD, Schmidt ST, Oh AK, Reinert SE, Zabbo CP. Digital imaging analysis of scar aesthetics. Adv Skin Wound Care. 2012;25(3):119-23.

48. Kim DW, Hwang NH, Yoon ES, Dhong ES, Park SH. Outcomes of ablative fractional laser scar treatment. Journal of plastic surgery and hand surgery. 2015:49(2):88-94.

49. Bray R, Forrester K, Leonard C, McArthur R, Tulip J, Lindsay R. Laser Doppler imaging of burn scars: a comparison of wavelength and scanning methods. Burns : journal of the International Society for Burn Injuries. 2003;29(3):199-206.

50. Ehrlich HP, Kelley SF. Hypertrophic scar: an interruption in the remodeling of repair-a laser Doppler blood flow study. Plast Reconstr Surg. 1992;90(6):993-8.

51. Hosoda G, Holloway GA, Heimbach DM. Laser Doppler flowmetry for the early detection of hypertrophic burn scars. The Journal of burn care \& rehabilitation. 1986;7(6):496-7.

52. Musgrave MA, Umraw N, Fish JS, Gomez M, Cartotto RC. The effect of silicone gel sheets on perfusion of hypertrophic burn scars. The Journal of burn care \& rehabilitation. 2002;23(3):208-14

53. Timar-Banu $O$, Beauregard $H$, Tousignant J, Lassonde $M$, Harris $P$, Viau G, et al. Development of noninvasive and quantitative methodologies for the assessment of chronic ulcers and scars in humans. Wound repair and regeneration : official publication of the Wound Healing Society [and] the European Tissue Repair. Society. 2001;9(2):123-32.

54. Page RE, Robertson GA, Pettigrew NM. Microcirculation in hypertrophic burn scars. Burns, including thermal injury. 1983;10(1):64-70.

55. Leung KS, Sher A, Clark JA, Cheng JC, Leung PC. Microcirculation in hypertrophic scars after burn injury. The Journal of burn care \& rehabilitation. 1989;10(5):436-44.

56. Clark JA, Leung KS, Cheng JC, Leung PC. The hypertrophic scar and microcirculation properties. Burns : journal of the International Society for Burn Injuries. 1996;22(6):447-50.

57. Forrester KR, Tulip J, Leonard C, Stewart C, Bray RC. A laser speckle imaging technique for measuring tissue perfusion. IEEE transactions on bio-medical engineering. 2004;51(11):2074-84.
58. Wittenberg GP, Fabian BG, Bogomilsky JL, Schultz LR, Rudner EJ, Chaffins ML, et al. Prospective, single-blind, randomized, controlled study to assess the efficacy of the 585-nm flashlamp-pumped pulsed-dye laser and silicone gel sheeting in hypertrophic scar treatment. Arch Dermatol. 1999;135(9):1049-55.

59. Allely RR, Van-Buendia LB, Jeng JC, White P, Wu J, Niszczak J, et al. Laser Doppler imaging of cutaneous blood flow through transparent face masks: a necessary preamble to computer-controlled rapid prototyping fabrication with submillimeter precision. Journal of burn care \& research : official publication of the American Burn Association. 2008;29(1):42-8.

60. Stewart CJ, Frank R, Forrester KR, Tulip J, Lindsay R, Bray RC. A comparison of two laser-based methods for determination of burn scar perfusion: laser Doppler versus laser speckle imaging. Burns : journal of the International Society for Burn Injuries. 2005;31(6):744-52.

61. moorFLPI-2 (Laser speckle contrast imager) [01/04/2015]. Available from: http://us.moor.co.uk/product/moorflpi-2-/291.

62. Prindeze NJ, Hoffman HA, Ardanuy JG, Zhang J, Carney BC, Moffatt LT, et al. Active Dynamic Thermography is a Sensitive Method for Distinguishing Burn Wound Conversion. Journal of burn care \& research : official publication of the American Burn Association. 2015.

63. Monstrey S, Hoeksema H, Verbelen J, Pirayesh A, Blondeel P. Assessment of burn depth and burn wound healing potential. Burns : journal of the International Society for Burn Injuries. 2008;34(6):761-9.

64. Hardwicke J, Thomson R, Bamford A, Moiemen N. A pilot evaluation study of high resolution digital thermal imaging in the assessment of burn depth. Burns: journal of the International Society for Burn Injuries. 2013;39(1):76-81.

65. Coster A, Klein Baltink H, Zilvold G. Thermographic assessment of healed burn wounds. Rays. 1985;10(3):85-8.

66. Horta R, Nascimento R, Vilas-Boas J, Sousa F, Orvalho V, Silva A, et al. Thermographic analysis of facially burned patients. Burns : journal of the International Society for Burn Injuries. 2015.

67. Bhedi A, Saxena AK, Gadani R, Patel R. Digital Photography and Transparency-Based Methods for Measuring Wound Surface Area. The Indian Journal of Surgery. 2013;75(2):111-4.

68. Chang AC, Dearman B, Greenwood JE. A Comparison of Wound Area Measurement Techniques: Visitrak Versus Photography. Eplasty. 2011;11:e18.

69. Cui J, Zhang J, Wang J, Xu M, Pei YH, Wang T, et al. Effect of topical application with mitomycin $C$ in the management of benign cicatricial airway stenosis. Chung-Hua Chieh Ho Ho Hu Hsi Tsa Chih Chinese Journal of Tuberculosis \& Respiratory Diseases. 2012;35(12):901-6.

70. Sugama J, Matsui Y, Sanada H, Konya C, Okuwa M, Kitagawa A. A study of the efficiency and convenience of an advanced portable Wound Measurement System (VISITRAK). J Clin Nurs. 2007;16(7):1265-9.

71. van Zuijlen PP, Angeles AP, Suijker MH, Kreis RW, Middelkoop E. Reliability and accuracy of techniques for surface area measurements of wounds and scars. The international journal of lower extremity wounds. 2004;3(1):7-11.

72. Berman B, Young VL, McAndrews J, et al. Objective Assessment of the Precision, Accuracy, and Reliability of a Measurement Method for Keloid Scar Volume (PARKS Study). Dermatologic surgery: official publication for American Society for Dermatologic Surgery. 2015.

73. 3dMD static systems [2nd September 2015]. Available from: http://www. 3dmd.com/\#3dmd-products.

74. Kim JE, Heo YS, Oh TS, Song HJ, Oh CH. The efficacy of cultured autologous fibroblast injection treatment for depressed acne scar and evaluation by stereoimage optical topometer. Journal of Dermatology Conference: 1st Eastern Asia Dermatology Congress, EADC2010 Fukuoka Japan Conference Start. 2010;37:77

75. Stekelenburg CM, van der Wal MB, Knol DL, de Vet HC, van Zuijlen PP. Threedimensional digital stereophotogrammetry: a reliable and valid technique for measuring scar surface area. Plast Reconstr Surg. 2013;132(1):204-11.

76. Lumenta DB, Kitzinger HB, Selig H, Kamolz LP. Objective quantification of subjective parameters in scars by use of a portable stereophotographic system. Ann Plast Surg. 2011;67(6):641-5.

77. Tanaka Y, Tsunemi Y, Kawashima M, Tatewaki N, Nishida H. Objective assessment of skin tightening in Asians using a water-filtered near-infrared (1,000-1,800 nm) device with contact-cooling and freezer-stored gel. Clin Cosmet Investig Dermatol. 2013;6:167-76.

78. Canfield Photography solutions [cited 2015 2nd September]. Available from: http://www.canfieldsci.com/imaging-systems/categories/photography-solutions/.

79. Tanaka Y. Long-term three-dimensional volumetric assessment of skin tightening using a sharply tapered non-insulated microneedle 
radiofrequency applicator with novel fractionated pulse mode in asians. Lasers Surg Med. 2015;47(8):626-33.

80. Urbanová $P$, Hejna $P$, Jurda M. Testing photogrammetry-based techniques for three-dimensional surface documentation in forensic pathology. Forensic Sci Int. 2015;250:77-86.

81. Ardehali B, Nouraei SA, Van Dam H, Dex E, Wood S, Nduka C. Objective assessment of keloid scars with three-dimensional imaging: quantifying response to intralesional steroid therapy. Plastic \& Reconstructive Surgery. 2007;119(2):556-61.

82. Hoeffelin H, Jacquemin D, Defaweux V, Nizet JL. A Methodological Evaluation of Volumetric Measurement Techniques including ThreeDimensional Imaging in Breast Surgery. BioMed Research International. 2014:2014:573249.

83. Gee Kee EL, Kimble RM, Stockton KA. 3D photography is a reliable burn wound area assessment tool compared to digital planimetry in very young children. Burns : journal of the International Society for Burn Injuries. 2015.

84. Bowling FL, King L, Fadavi H, Paterson JA, Preece K, Daniel RW, et al. An assessment of the accuracy and usability of a novel optical wound measurement system. Diabetic medicine : a journal of the British Diabetic Association. 2009;26(1):93-6.

85. Bowling FL, King L, Paterson JA, Hu J, Lipsky BA, Matthews DR, et al. Remote assessment of diabetic foot ulcers using a novel wound imaging system. Wound repair and regeneration : official publication of the Wound Healing Society [and] the European Tissue Repair. Society. 2011;19(1):25-30.

86. Paterson J. Eykona Medical Imaging FAQ. EYK/AA/021 rev02 ed.

87. Lifeviz Mini Technical specifications. Quantificare.

88. Vectra H1 Technical specifications: Canfield Imaging systems Inc.; [9th December 2015]. Available from: http://www.canfieldsci.com/imagingsystems/vectra-h1-3d-imaging-system/.

89. Raytrix Light field/ Plenoptic 3D cameras [cited 2015 2nd September]. Available from: http://www.raytrix.de/produkte/.

90. Straub J, Kerlin S. Development of a Large, Low-Cost, Instant 3D Scanner. Technologies. 2014;2(2):76.

91. Pilley MJ, Hitchens C, Rose G, Alexander S, Wimpenny DI. The use of non-contact structured light scanning in burns pressure splint construction. Burns : journal of the International Society for Burn Injuries. 2011;37(7):1168-73.

92. Kovacs L, Eder M, Hollweck R, Zimmermann A, Settles M, Schneider A, et al. Comparison between breast volume measurement using 3D surface imaging and classical techniques. Breast. 2007;16(2):137-45.

93. Taylor B, McGrouther DA, Bayat A. Use of a non-contact 3D digitiser to measure the volume of keloid scars: a useful tool for scar assessment. Journal of plastic, reconstructive \& aesthetic surgery : JPRAS. 2007;60(1):87-94

94. Powers PS, Sarkar S, Goldgof DB, Cruse CW, Tsap LV. Scar assessment: current problems and future solutions. Journal of Burn Care \& Rehabilitation. 1999;20(1 Pt 1):54-60. discussion 53.

95. Haller HL, Dirnberger J, Giretzlehner M, Rodemund C, Kamolz L. "Understanding burns": Research project BurnCase 3D-Overcome the limits of existing methods in burns documentation. Burns : journal of the International Society for Burn Injuries. 2009;35(3):311-7.

96. Thumfart S, Giretzlehner M, Holler J, Ehrenmuller M, Pfurtscheller K, Haller H, et al. Proportionally correct 3D models of infants, children and adolescents for precise burn size measurement. Hannover, Germany: European Burns Association Congress; 2015.

97. Wurzer P, Giretzlehner M, Klein D. SY, Haller H. L., Branski L. K., Benjamin N, et al. Burncase 3D software validation study: Burn size measurement accuracy, test-retest reliability and inter-rater reliability. European Burns Association Congress 2015. Hannover, Germany: Annals of Burns and Fire Disasters-Supplement EBA; 2015.

98. Cheng W, Saing H, Zhou H, Han Y, Peh W, Tam PK. Ultrasound assessment of scald scars in Asian children receiving pressure garment therapy. J Pediatr Surg. 2001;36(3):466-9.

99. Wang ZY, Zhang J, Lu SL. Objective evaluation of burn and post-surgical scars and the accuracy of subjective scar type judgment. Chin Med J. 2008; 121(24):2517-20.

100. Sawada Y. A method of recording and objective assessment of hypertrophic burn scars. Burns : journal of the International Society for Burn Injuries. 1994;20(1):76-8.

101. Hambleton J, Shakespeare PG, Pratt BJ. The progress of hypertrophic scars monitored by ultrasound measurements of thickness. Burns : journal of the International Society for Burn Injuries. 1992;18(4):301-7.
102. Li-Tsang CW, Lau JC, Chan CC. Prevalence of hypertrophic scar formation and its characteristics among the Chinese population. Burns : journal of the International Society for Burn Injuries. 2005;31(5):610-6.

103. Lau JC, Li-Tsang CW, Zheng YP. Application of tissue ultrasound palpation system (TUPS) in objective scar evaluation. Burns : journal of the International Society for Burn Injuries. 2005;31(4):445-52.

104. Lai H-yC. Study of pressure effect on hypertrophic scar tissues: The Hong Kong Polytechnic University. 2010.

105. Lau C-mJ. A prospective randomized clinical trial to compare the effectiveness of pressure therapy, silicone gel sheeting and the combined therapy on postsurgical hypertrophic scar: The Hong Kong Polytechnic University. 2006.

106. Nedelec B, Correa JA, Rachelska G, Armour A, LaSalle L. Quantitative measurement of hypertrophic scar: interrater reliability and concurrent validity. Journal of burn care \& research : official publication of the American Burn Association. 2008;29(3):501-11.

107. Van den Kerckhove E, Colla C, Van Brussel M. Pressure Therapy: Does it work? Düsseldorf: German Medical Science GMS Publishing House; 2010.

108. Qui L, Jin X, Kingston PA, Luo X, Ding X. Experimental study on BMSCs transfected by endogene inhibiting hypertrophic scar. Chung-Kuo Hsiu Fu Chung Chien Wai Ko Tsa Chih/Chinese Journal of Reparative \& Reconstructive Surgery. 2008;22(2):212-6.

109. Du YC, Lin CM, Chen YF, Chen CL, Chen T. Implementation of a burn scar assessment system by ultrasound techniques. Conference proceedings : Annual International Conference of the IEEE Engineering in Medicine and Biology Society IEEE Engineering in Medicine and Biology Society Annual Conference. 2006;1:2328-31.

110. Danin A, Georgesco G, Le Touze A, Penaud A, Quignon R, Zakine G. Assessment of burned hands reconstructed with Integra by ultrasonography and elastometry. Burns : journal of the International Society for Burn Injuries. 2012;38(7):998-1004.

111. Lacarrubba F, Verzi AE, Tedeschi A, Catalfo P, Nasca MR, Micali G. Clinical and ultrasonographic correlation of acne scars. Dermatol Surg. 2013;39(11):1683-8.

112. Li JQ, Li-Tsang CW, Huang YP, Chen Y, Zheng YP. Detection of changes of scar thickness under mechanical loading using ultrasonic measurement. Burns : journal of the International Society for Burn Injuries. 2013;39(1):89-97.

113. Zhuang A, Nguyen TA, Naheedy J, Krakowski A. Use of intraoperative highdefinition ultrasound to accurately gauge scar thickness and identify intrascar anatomy during multimodal revision of a hypertrophic burn scar. Lasers Surg Med. 2015;47:54-5.

114. Katz SM, Frank DH, Leopold GR, Wachtel TL. Objective measurement of hypertrophic burn scar: a preliminary study of tonometry and ultrasonography. Ann Plast Surg. 1985;14(2):121-7.

115. Zmudzinska M, Czarnecka-Operacz M, Silny W. Principles of dermatologic ultrasound diagnostics. Acta Dermatovenerol Croat. 2008;16(3):126-9.

116. Wohlrab J, Wohlrab D, Finke R, Fischer M, Marsch WC. Ultrasonographic characterization of burn scars in children. Unfallchirurg. 2000;103(9):754-60.

117. Van den Kerckhove E, Staes F, Flour M, Stappaerts K, Boeckx W. Reproducibility of repeated measurements on post-burn scars with Dermascan C. Skin research and technology : official journal of International Society for Bioengineering and the Skin (ISBS) [and] International Society for Digital Imaging of Skin (ISDIS) [and] International Society for Skin Imaging (ISSI). 2003;9(1):81-4.

118. Nedelec B, Shankowsky HA, Tredget EE. Rating the resolving hypertrophic scar: Comparison of the Vancouver Scar Scale and scar volume. J Burn Care Rehabil. 2000;21(3):205-12.

119. Qui L, Jin X, Kingston PA, Luo X, Ding X. [Experimental study on BMSCs transfected by endogene inhibiting hypertrophic scar]. Zhongguo xiu fu chong jian wai ke za zhi $=$ Zhongguo xiufu chongjian waike zazhi $=$ Chinese journal of reparative and reconstructive surgery. 2008;22(2):212-6.

120. Cilip CM, Allaf ME, Fried NM. Application of optical coherence tomography and high-frequency ultrasound imaging during noninvasive laser vasectomy. J Biomed Opt. 2012;17(4):046006.

121. Episcan [cited 2015 January]. Available from: http://www.longportinc.com/ about/episcan.html.

122. Skin scanner DUB [cited 2015 January]. Available from: http://www.eotechsa.com/Life-science/Systems/DUBSkin-Scanner/Products/t1/r9/i107.

123. Verhaegen PD, van der Wal MB, Middelkoop E, van Zuijlen PP. Objective scar assessment tools: a clinimetric appraisal. Plast Reconstr Surg. 2011;127(4):1561-70.

124. Kautzky F, Dahm MW, Drosner M, Köhler LD, Vogt H-J, Borelli S. Direct profilometry of the skin: its reproducibility and variability. J Eur Acad Dermatol Venereol. 1995;5(1):15-23. 
125. Lagarde JM, Rouvrais C, Black D, Diridollou S, Gall Y. Skin topography measurement by interference fringe projection: a technical validation. Skin research and technology : official journal of International Society for Bioengineering and the Skin (ISBS) [and] International Society for Digital Imaging of Skin (ISDIS) [and] International Society for Skin Imaging (ISSI) 2001;7(2):112-21.

126. Nardin P, Nita D, Mignot J. Automation of a series of cutaneous topography measurements from silicon rubber replicas. Skin research and technology : official journal of International Society for Bioengineering and the Skin (ISBS) [and] International Society for Digital Imaging of Skin (ISDIS) [and] International Society for Skin Imaging (ISSI). 2002;8(2):112-7.

127. Fischer TW, Wigger-Alberti W, Elsner P. Direct and non-direct measurement techniques for analysis of skin surface topography. Skin Pharmacol Appl Ski Physiol. 1999;12(1-2):1-11.

128. De Paepe K, Lagarde JM, Gall Y, Roseeuw D, Rogiers V. Microrelief of the skin using a light transmission method. Arch Dermatol Res. 2000; 292(10):500-10.

129. Bloemen MC, van Gerven MS, van der Wal MB, Verhaegen PD, Middelkoop E. An objective device for measuring surface roughness of skin and scars. J Am Acad Dermatol. 2011;64(4):706-15.

130. Barolet D, Boucher A. Prophylactic low-level light therapy for the treatment of hypertrophic scars and keloids: a case series. Lasers Surg Med. 2010;42(6):597-601.

131. Kottner J, Schario M, Garcia Bartels N, Pantchechnikova E, Hillmann K, Blume-Peytavi U. Comparison of two in vivo measurements for skin surface topography. Skin research and technology : official journal of International Society for Bioengineering and the Skin (ISBS) [and] International Society for Digital Imaging of Skin (ISDIS) [and] International Society for Skin Imaging (ISSI). 2013;19(2):84-90.

132. Zhao L, Hung LK, Zhang YT. Electrical properties of normal and scarred skin. In: Chang HK, Zhang YT, editors. Proceedings of the 20th Annual International Conference of the leee Engineering in Medicine and Biology Society, Vol 20, Pts 1-6: Biomedical Engineering Towards the Year 2000 and Beyond. Proceedings of Annual International Conference of the leee Engineering in Medicine and Biology Society. 201998. p. 2917-20.

133. Moloney EC, Brunner M, Alexander AJ, Clark J. Quantifying fibrosis in head and neck cancer treatment: An overview. Head and Neck-Journal for the Sciences and Specialties of the Head and Neck. 2015;37(8):1225-31.

134. Dematte MF, Gemperli R, Salles AG, Dolhnikoff M, Lancas T, Nascimento Saldiva $\mathrm{PH}$, et al. Mechanical evaluation of the resistance and elastance of post-burn scars after topical treatment with tretinoin. Clinics. 2011;66(11): 1949-54.

135. Clark JA, Cheng JC, Leung KS. Mechanical properties of normal skin and hypertrophic scars. Burns : journal of the International Society for Burn Injuries. 1996;22(6):443-6.

136. Gunner CW, Hutton WC, Burlin TE. The mechanical properties of skin in vivo-a portable hand-held extensometer. The British journal of dermatology. 1979;100(2):161-3.

137. Lim KH, Chew CM, Chen PC, Jeyapalina S, Ho HN, Rappel JK, et al. New extensometer to measure in vivo uniaxial mechanical properties of human skin. J Biomech. 2008:41(5):931-6.

138. Thacker JG. lachetta FA, Allaire PE. In vivo extensometer for measurement of the biomechanical properties of human skin. The Review of scientific instruments. 1977:48(2):181-5.

139. Clark JA, Cheng JC, Leung KS, Leung PC. Mechanical characterisation of human postburn hypertrophic skin during pressure therapy. J Biomech. 1987;20(4):397-406.

140. Chu BM, Brody G. Nondestructive measurements of the properties of healing burn scars. Medical instrumentation. 1975;9(3):139-42

141. Bartell TH, Monafo WW, Mustoe TA. A new instrument for serial measurements of elasticity in hypertrophic scar. J Burn Care Rehabil. 1988; 9(6):657-60.

142. Rennekampff HO, Rabbels J, Reinhard V, Becker ST, Schaller HE. Comparing the Vancouver Scar Scale with the cutometer in the assessment of donor site wounds treated with various dressings in a randomized trial. Journal of burn care \& research : official publication of the American Burn Association. 2006;27(3):345-51.

143. Klosova H, Stetinsky J, Bryjova I, Hledik S, Klein L. Objective evaluation of the effect of autologous platelet concentrate on post-operative scarring in deep burns. Burns : journal of the International Society for Burn Injuries. 2013; 39(6):1263-76.
144. Nguyen DQ, Potokar TS, Price P. An objective long-term evaluation of Integra (a dermal skin substitute) and split thickness skin grafts, in acute burns and reconstructive surgery. Burns : journal of the International Society for Burn Injuries. 2010;36(1):23-8.

145. Rahmanian-Schwarz A, Beiderwieden A, Willkomm LM, Amr A, Schaller HE, Lotter O. A clinical evaluation of Biobrane((R)) and Suprathel((R)) in acute burns and reconstructive surgery. Burns : journal of the International Society for Burn Injuries. 2011;37(8):1343-8.

146. Fong SS, Hung LK, Cheng JC. The cutometer and ultrasonography in the assessment of postburn hypertrophic scar-a preliminary study. Burns : journal of the International Society for Burn Injuries. 1997;23 Suppl 1:S12-8.

147. Draaijers L, Botman YA, Tempelman FR, Kreis RW, Middelkoop E, van Zuijlen PP. Skin elasticity meter or subjective evaluation in scars: a reliability assessment. Burns : journal of the International Society for Burn Injuries. 2004;30(2):109-14

148. Selig HF, Keck M, Lumenta DB, Mittlbock M, Kamolz LP. The use of a polylactide-based copolymer as a temporary skin substitute in deep dermal burns: 1-year follow-up results of a prospective clinical noninferiority trial. Wound repair and regeneration : official publication of the Wound Healing Society [and] the European Tissue Repair Society. 2013;21(3):402-9.

149. Sin P, Stupka I, Brychta P. Evaluation and comparison of composite and split-thickness skin grafts using cutometer mpa 580. Annals of burns and fire disasters. 2010;23(4):208-13.

150. van Zuijlen PP, Vloemans JF, van Trier AJ, Suijker MH, van Unen E, Groenevelt F, et al. Dermal substitution in acute burns and reconstructive surgery: a subjective and objective long-term follow-up. Plast Reconstr Surg. 2001;108(7):1938-46.

151. Fournier R, Pierard GE. Skin tensile strength modulation by compressive garments in burn patients. A pilot study. Journal of medical engineering \& technology. 2000;24(6):277-80.

152. Krusche T, Worret WI. Mechanical properties of keloids in vivo during treatment with intralesional triamcinolone acetonide. Arch Dermatol Res. 1995;287(3-4):289-93.

153. Matsuzaki K, Kumagai N, Fukushi S, Ohshima H, Tanabe M, Ishida H. Cultured epithelial autografting on meshed skin graft scars: evaluation of skin elasticity. The Journal of burn care \& rehabilitation. 1995;16(5):496-502.

154. Nguyen NT, Roberge D, Freeman CR, Wong C, Hines J, Turcotte RE. Skin Elasticity as a Measure of Radiation Fibrosis: Is it Reproducible and Does it Correlate with Patient and Physician-reported Measures? Technology in cancer research \& treatment. 2013.

155. Rennekampff HO, Rabbels J, Pfau M. Schaller HE. Kongressband / Deutsche Gesellschaft fur Chirurgie Deutsche Gesellschaft fur Chirurgie Kongress. 2002;119:749-55. Evaluating scar development with objective computerassisted viscoelastic measurement.

156. Anthonissen M, Daly D, Fieuws S, Massage P, Van Brussel M, Vranckx J, et al. Measurement of elasticity and transepidermal water loss rate of burn scars with the Dermalab((R)). Burns : journal of the International Society for Burn Injuries. 2013;39(3):420-8.

157. Spann K, Mileski WJ, Atiles L, Purdue G, Hunt J. The 1996 Clinical Research award. Use of a pneumatonometer in burn scar assessment. The Journal of burn care \& rehabilitation. 1996;17(6 Pt 1):515-7.

158. Lye I, Edgar DW, Wood FM, Carroll S. Tissue tonometry is a simple, objective measure for pliability of burn scar: is it reliable? Journal of burn care \& research : official publication of the American Burn Association. 2006;27(1):82-5.

159. Akita S, Akino K, Yakabe A, Imaizumi T, Tanaka K, Anraku K, et al. Combined surgical excision and radiation therapy for keloid treatment. The Journal of craniofacial surgery. 2007;18(5):1164-9.

160. Merkel PA, Silliman NP, Denton CP, Furst DE, Khanna D, Emery P, et al. Validity, reliability, and feasibility of durometer measurements of scleroderma skin disease in a multicenter treatment trial. Arthritis Rheum. 2008;59(5):699-705.

161. Magliaro A, Romanelli M. Skin hardness measurement in hypertrophic scars. Wounds-a Compendium of Clinical Research and Practice. 2003;15(3):66-70.

162. Esposito G, Ziccardi P, Scioli M, Pappone N, Scuderi N. The use of a modified tonometer in burn scar therapy. The Journal of burn care \& rehabilitation. 1990;11(1):86-90

163. Wernicke AG, Greenwood EA, Coplowitz S, Parashar B, Kulidzhanov F, Christos PJ, et al. Tissue compliance meter is a more reproducible method of measuring radiation-induced fibrosis than late effects of normal tissuesubjective objective management analytical in patients treated with intracavitary brachytherapy accelerated partial breast irradiation: results of a prospective trial. Breast J. 2013;19(3):250-8. 
164. Corica GF, Wigger NC, Edgar DW, Wood FM, Carroll S. Objective measurement of scarring by multiple assessors: is the tissue tonometer a reliable option? Journal of burn care \& research : official publication of the American Burn Association. 2006;27(4):520-3.

165. Boyce ST, Supp AP, Wickett RR, Hoath SB, Warden GD. Assessment with the dermal torque meter of skin pliability after treatment of burns with cultured skin substitutes. The Journal of burn care \& rehabilitation. 2000;21(1 Pt 1):55-63.

166. McHugh AA, Fowlkes BJ, Maevsky El, Smith Jr DJ, Rodriguez JL, Garner WL. Biomechanical alterations in normal skin and hypertrophic scar after thermal injury. The Journal of burn care \& rehabilitation. 1997;18(2):104-8.

167. Popovic G, Sarvazyan A, Ponomarjev V, Vucelic D. Method and device for noninvasive acoustic testing of elasticity of soft biological tissues. Google Patents. 1992

168. Verhaegen PD, Res EM, van Engelen A, Middelkoop E, van Zuijlen PP. A reliable, non-invasive measurement tool for anisotropy in normal skin and scar tissue. Skin research and technology : official journal of International Society for Bioengineering and the Skin (ISBS) [and] International Society for Digital Imaging of Skin (ISDIS) [and] International Society for Skin Imaging (ISSI). 2010;16(3):325-31.

169. Ferriero G, Vercelli S, Salgovic L, Stissi V, Sartorio F. Validation of a new device to measure postsurgical scar adherence. Phys Ther. 2010;90(5): 776-83.

170. Tsap LV, Goldgof DB, Sarkar S, Powers PS. A vision-based technique for objective assessment of burn scars. IEEE Trans Med Imaging. 1998; 17(4):620-33.

171. Zhang Y, Goldgof DB, Sarkar S, Tsap LV. A modeling approach for burn scar assessment using natural features and elastic property. IEEE Trans Med Imaging. 2004;23(10):1325-9.

172. Larrabee Jr WF. A finite element model of skin deformation. I. Biomechanics of skin and soft tissue: a review. Laryngoscope. 1986;96(4):399-405.

173. Zhang Y, Goldgof DB, Sarkar S, Tsap LV. Model-based nonrigid motion analysis using natural feature adaptive mesh. In: Sanfeliu A, Villanueva JJ, Vanrell M, Alquezar R, Huang T, Serra J, editors. 15th International Conference on Pattern Recognition, Vol 3, Proceedings: Image, Speech and Signal Processing. International Conference on Pattern Recognition. 2000. p. 831-5.

174. Palmieri TL, Petuskey K, Bagley A, Takashiba S, Greenhalgh DG, Rab GT Alterations in functional movement after axillary burn scar contracture: a motion analysis study. The Journal of burn care \& rehabilitation. 2003;24(2): 104-8.

175. Parry I, Walker K, Niszczak J, Palmieri T, Greenhalgh D. Methods and tools used for the measurement of burn scar contracture. Journal of burn care \& research : official publication of the American Burn Association. 2010;31(6):888-903.

176. Rab G, Petuskey K, Bagley A. A method for determination of upper extremity kinematics. Gait \& posture. 2002;15(2):113-9.

177. van der Helm FC, Pronk GM. Three-dimensional recording and description of motions of the shoulder mechanism. J Biomech Eng. 1995;117(1):27-40

178. Koller R, Kargul G, Giovanoli P, Meissl G, Frey M. Quantification of functional results after facial burns by the faciometer. Burns : journal of the International Society for Burn Injuries. 2000;26(8):716-23.

179. Berry RB, Tan OT, Cooke ED, Gaylarde PM, Bowcock SA, Lamberty BG, et al. Transcutaneous oxygen tension as an index of maturity in hypertrophic scars treated by compression. Br J Plast Surg. 1985;38(2):163-73.

180. Ichioka S, Ando T, Shibata M, Sekiya N, Nakatsuka T. Oxygen consumption of keloids and hypertrophic scars. Ann Plast Surg. 2008;60(2):194-7.

181. Rodrigues LM, Roberto MA. Characterization strategies for the functional assessment of the cutaneous lesion. Burns : journal of the International Society for Burn Injuries. 2006;32(7):797-801.

182. Fluhr JW, Feingold KR, Elias PM. Transepidermal water loss reflects permeability barrier status: validation in human and rodent in vivo and ex vivo models. Exp Dermatol. 2006:15(7):483-92.

183. Rosado C, Pinto P, Rodrigues LM. Comparative assessment of the performance of two generations of Tewameter: TM210 and TM300. Int J Cosmet Sci. 2005;27(4):237-41.

184. De Paepe K, Houben E, Adam R, Wiesemann F, Rogiers V. Validation of the VapoMeter, a closed unventilated chamber system to assess transepidermal water loss vs. the open chamber Tewameter. Skin research and technology official journal of International Society for Bioengineering and the Skin (ISBS) [and] International Society for Digital Imaging of Skin (ISDIS) [and] International Society for Skin Imaging (ISSI). 2005;11(1):61-9.
185. Anthonissen M. Assessment and conservative treatments of burn scars; Evaluatie en conservatieve behandeling van littekens na brandwonden. 2015.

186. Clarys P, Clijsen R, Taeymans J, Barel AO. Hydration measurements of the stratum corneum: comparison between the capacitance method (digital version of the Corneometer CM 825(R)) and the impedance method (Skicon-200EX(R)). Skin research and technology : official journal of International Society for Bioengineering and the Skin (ISBS) [and] International Society for Digital Imaging of Skin (ISDIS) [and] International Society for Skin Imaging (ISSI). 2012;18(3):316-23.

187. O'Goshi K, Serup J. Skin conductance; validation of Skicon-200EX compared to the original model, Skicon-100. Skin research and technology : official journal of International Society for Bioengineering and the Skin (ISBS) [and] International Society for Digital Imaging of Skin (ISDIS) [and] International Society for Skin Imaging (ISSI). 2007;13(1):13-8.

188. Magnusson M, Papini RP, Rea SM, Reed CC, Wood FM. Cultured autologous keratinocytes in suspension accelerate epithelial maturation in an in vivo wound model as measured by surface electrical capacitance. Plast Reconstr Surg. 2007;119(2):495-9.

189. Anthonissen M, Daly D, Peeters $R$, Van Brussel M, Fieuws S, Moortgat $P$, et al. Reliability of Repeated Measurements on Post-Burn Scars with Corneometer CM 825. Skin research and technology : official journal of International Society for Bioengineering and the Skin (ISBS) [and] International Society for Digital Imaging of Skin (ISDIS) [and] International Society for Skin Imaging (ISSI). 2014

190. Nuutinen J. Skin dielectric constant at high radiofrequency with special emphasis on radiation-induced late skin reaction [Ph.D. thesis]. Kuopio, Finland: Kuopio University Publications C. Natural and Environmental Sciences 55; 1997.

191. Lahtinen T, Nuutinen J, Alanen E, Turunen M, Nuortio L, Usenius T, et al. Quantitative assessment of protein content in irradiated human skin. Int J Radiat Oncol Biol Phys. 1999;43(3):635-8.

192. Suetake T, Sasai S, Zhen YX, Ohi T, Tagami H. Functional analyses of the stratum corneum in scars. Sequential studies after injury and comparison among keloids, hypertrophic scars, and atrophic scars. Arch Dermatol. 1996; 132(12):1453-8

193. Ghassemi P, Travis TE, Moffatt LT, Shupp JW, Ramella-Roman JC. A polarized multispectral imaging system for quantitative assessment of hypertrophic scars. Biomedical optics express. 2014;5(10):3337-54.

194. Ghassemi P, Shupp JW, Moffatt LT, Ramella-Roman JC. A Novel Spectral Imaging System for Quantitative Analysis of Hypertrophic Scar. In: Kollias N, Choi B, Zeng H, Kang HW, Knudsen BE, Wong BJF, et al., editors. Photonic Therapeutics and Diagnostics Ix. Proceedings of SPIE. 85652013.

195. Drexler W, Fujimoto JG. State-of-the-art retinal optical coherence tomography. Prog Retin Eye Res. 2008;27(1):45-88.

196. Alex A, Povazay B, Hofer B, Popov S, Glittenberg C, Binder S, et al. Multispectral in vivo three-dimensional optical coherence tomography of human skin. J Biomed Opt. 2010;15(2):026025.

197. Welzel J, Lankenau E, Birngruber R, Engelhardt R. Optical coherence tomography of the human skin. J Am Acad Dermatol. 1997:37(6):958-63.

198. Gambichler T, Moussa G, Sand M, Sand D, Altmeyer P, Hoffmann K. Applications of optical coherence tomography in dermatology. J Dermatol Sci. 2005;40(2):85-94

199. Welzel J. Optical coherence tomography in dermatology: a review. Skin research and technology: official journal of International Society for Bioengineering and the Skin (ISBS) [and] International Society for Digital Imaging of Skin (ISDIS) [and] International Society for Skin Imaging (ISSI). 2001;7(1):1-9.

200. Steiner R, Kunzi-Rapp K, Scharffetter-Kochanek K. Optical Coherence Tomography: Clinical Applications in Dermatology. Medical Laser Application. 2003;18(3):249-59.

201. Liew YM, McLaughlin RA, Gong P, Wood FM, Sampson DD. In vivo assessment of human burn scars through automated quantification of vascularity using optical coherence tomography. J Biomed Opt. 2013;18(6):061213.

202. Gong P, Chin L, Es'haghian S, Liew YM, Wood FM, Sampson DD, et al. Imaging of skin birefringence for human scar assessment using polarizationsensitive optical coherence tomography aided by vascular masking. J Biomed Opt. 2014;19(12):126014.

203. Gong P, McLaughlin RA, Liew YM, Munro PR, Wood FM, Sampson DD. Assessment of human burn scars with optical coherence tomography by imaging the attenuation coefficient of tissue after vascular masking. J Biomed Opt. 2014;19(2):21111. 
204. Babalola O, Mamalis A, Lev-Tov H, Jagdeo J. Optical coherence tomography (OCT) of collagen in normal skin and skin fibrosis. Arch Dermatol Res. 2014;306(1):1-9.

205. Choi WJ, Reif R, Yousefi S, Wang RK. Improved microcirculation imaging of human skin in vivo using optical microangiography with a correlation mapping mask. J Biomed Opt. 2014;19(3):36010.

206. Wang XQ, Mill J, Kravchuk O, Kimble RM. Ultrasound assessed thickness of burn scars in association with laser Doppler imaging determined depth of burns in paediatric patients. Burns : journal of the International Society for Burn Injuries. 2010;36(8):1254-62.

207. Lo WC, Villiger M, Golberg A, Broelsch GF, Khan S, Lian CG, et al, Longitudinal, 3D In Vivo Imaging of Collagen Remodeling in Murine Hypertrophic Scars using Polarization-sensitive Optical Frequency Domain Imaging. The Journal of investigative dermatology. 2015.

208. Eraud J, Gonnelli D, Carmassi M, Bruzzese L, Andrac-Meyer L, Casanova D, et al. Differential diagnosis between keloid and hypertrophic scars: a new approach by full-field optical coherence tomography. Ann Chir Plast Esthet. 2014;59(4):253-60.

209. Moshref SS, Mufti ST. Keloid and hypertrophic scars: comparative histopathological and immunohistochemical study. Med Sci. 2010;17:3-22.

210. Chen G, Chen J, Zhuo S, Xiong S, Zeng H, Jiang X, et al. Nonlinear spectral imaging of human hypertrophic scar based on two-photon excited fluorescence and second-harmonic generation. The British journal of dermatology. 2009;161(1):48-55.

211. Chen J, Zhuo S, Jiang X, Zhu X, Zheng L, Xie S, et al. Multiphoton microscopy study of the morphological and quantity changes of collagen and elastic fiber components in keloid disease. J Biomed Opt. 2011;16(5):051305.

212. Brewer MB, Yeh A, Torkian B, Sun CH, Tromberg BJ, Wong BJ. Multiphoton imaging of excised normal skin and keloid scar: preliminary investigations. In: Bartels KE, Bass LS, DeRiese WTW, Gregory KW, Hirschberg H, Katzir A, et al., editors. Lasers in Surgery: Advanced Characterization, Therapeutics, and Systems Xiv. Proceedings of the Society of Photo-Optical Instrumentation Engineers (Spie). 53122004. p. 204-8.

213. Chen A, Liu PY, McNeilly C, Cuttle L, Kempf M, Kendall M, et al. Collagen deposition assessment in burn scar tissue using second harmonic generation and multi-photon microscopy. J Investig Dermatol. 2010;130:S16-S.

214. Stoller P, Celliers PM, Reiser KM, Rubenchik AM. Imaging collagen orientation using polarization-modulated second harmonic generation. In: Periasamy A, So PTC, editors. Multiphoton Microscopy in the Biomedical Sciences li. Proceedings of the Society of Photo-Optical Instrumentation Engineers (Spie). 46202002. p. 157-65.

215. Kelf TA, Gosnell M, Sandnes B, Guller AE, Shekhter AB, Zvyagin AV. Scar tissue classification using nonlinear optical microscopy and discriminant analysis. J Biophotonics. 2012;5(2):159-67.

216. Da Costa V, Wei R, Lim R, Sun CH, Brown JJ, Wong BJ. Nondestructive imaging of live human keloid and facial tissue using multiphoton microscopy. Arch Facial Plast Surg. 2008;10(1):38-43.

217. Zhu XQ, Zhuo SM, Zheng LQ, Lu KC, Jiang XS, Chen JX, et al. Quantified characterization of human cutaneous normal scar using multiphoton microscopy. J Biophotonics. 2010;3(1-2):108-16.

218. de Vries HJ, Enomoto DN, van Marle J, van Zuijlen PP, Mekkes JR, Bos JD. Dermal organization in scleroderma: the fast Fourier transform and the laser scatter method objectify fibrosis in nonlesional as well as lesional skin. Laboratory investigation; a journal of technical methods and pathology. 2000;80(8):1281-9.

219. Konig K, Riemann I. High-resolution multiphoton tomography of human skin with subcellular spatial resolution and picosecond time resolution. J Biomed Opt. 2003;8(3):432-9.

220. Chen ACH, McNeilly C, Liu APY, Flaim CJ, Cuttle L, Kendall M, et al. Second harmonic generation and multiphoton microscopic detection of collagen without the need for species specific antibodies. Burns : journal of the International Society for Burn Injuries. 2011;37(6):1001-9.

221. Jiang $Y$, Tong $Y$, Xiao T, Lu S. Phase-contrast microtomography with synchrotron radiation technology: a new noninvasive technique to analyze the three-dimensional structure of dermal tissues. Dermatology. 2012;225(1):75-80.

222. Theer $P$, Hasan MT, Denk W. Two-photon imaging to a depth of 1000 microm in living brains by use of a Ti:Al2O3 regenerative amplifier. Opt Lett. 2003;28(12):1022-4.

223. Tseng SH, Hsu CK, Yu-Yun Lee J, Tzeng SY, Chen WR, Liaw YK. Noninvasive evaluation of collagen and hemoglobin contents and scattering property of in vivo keloid scars and normal skin using diffuse reflectance spectroscopy: pilot study. J Biomed Opt. 2012;17(7):077005.
224. Rajadhyaksha M, Gonzalez S, Zavislan JM, Anderson RR, Webb RH. In vivo confocal scanning laser microscopy of human skin II: advances in instrumentation and comparison with histology. The Journal of investigative dermatology. 1999;113(3):293-303.

225. Rolfe H, Wurm E, Gilmore S. An investigation of striae distensae using reflectance confocal microscopy. The Australasian journal of dermatology. 2012;53(3):181-5.

226. Nehal KS, Gareau D, Rajadhyaksha M. Skin imaging with reflectance confocal microscopy. Seminars in cutaneous medicine and surgery. 2008;27(1):37-43.

227. Chang SK, Mirabal YN, Atkinson EN, Cox D, Malpica A, Follen M, et al. Combined reflectance and fluorescence spectroscopy for in vivo detection of cervical pre-cancer. J Biomed Opt. 2005;10(2):024031.

228. Gisquet H, Liu H, Blondel WC, Leroux A, Latarche C, Merlin JL, et al. Intradermal tacrolimus prevent scar hypertrophy in a rabbit ear model: a clinical, histological and spectroscopical analysis. Skin research and technology : official journal of International Society for Bioengineering and the Skin (ISBS) [and] International Society for Digital Imaging of Skin (ISDIS) [and] International Society for Skin Imaging (ISSI). 2011; 17(2):160-6.

229. Liu HH, Gisquet H, Guillemin F, Blondel W. Bimodal spectroscopy for in vivo characterization of hypertrophic skin tissue: pre-clinical experimentation, spectral data selection and classification. In: Ramanujam N, Popp J, editors. Clinical and Biomedical Spectroscopy and Imaging li. Proceedings of SPIE. 80872011.

230. Hsu CK, Tzeng SY, Yang CC, Lee JY, Huang LL, Chen WR, et al. Non-invasive evaluation of therapeutic response in keloid scar using diffuse reflectance spectroscopy. Biomedical optics express. 2015;6(2):390-404.

231. Bessonart MN, Macedo N, Carmona C. High resolution B-scan ultrasound of hypertrophic scars. Skin research and technology : official journal of International Society for Bioengineering and the Skin (ISBS) [and] International Society for Digital Imaging of Skin (ISDIS) [and] International Society for Skin Imaging (ISSI). 2005;11(3):185-8.

232. Gangemi EN, Carnino R, Stella M. Videocapillaroscopy in postburn scars: in vivo analysis of the microcirculation. Burns : journal of the International Society for Burn Injuries. 2010;36(6):799-805.

233. Campanati A, Savelli A, Sandroni L, Marconi B, Giuliano A, Giuliodori K, et al. Effect of allium cepa-allantoin-pentaglycan gel on skin hypertrophic scars: clinical and video-capillaroscopic results of an open-label, controlled, nonrandomized clinical trial. Dermatologic surgery : official publication for American Society for Dermatologic Surgery. 2010;36(9):1439-44.

234. Pasqui AL, Pastorelli M, Puccetti L, Beerman U, Biagi F, Camarri A, et al. Microvascular assessment in Behcet disease: videocapillaroscopic study. Int J Tissue React. 2003;25(3):105-15.

235. Hern S, Mortimer PS. In vivo quantification of microvessels in clinically uninvolved psoriatic skin and in normal skin. The British journal of dermatology. 2007;156(6):1224-9.

236. Lamah M, Chaudhry H, Mortimer PS, Dormandy JA. Repeatability of intravital capillaroscopic measurement of capillary density. International journal of microcirculation, clinical and experimental / sponsored by the European Society for Microcirculation. 1996;16(1):23-9.

237. Yoo MG, Kim $\Vdash$. Keloids and hypertrophic scars: characteristic vascular structures visualized by using dermoscopy. Ann. 2014;26(5):603-9.

238. Wei Y, Li-Tsang CW, Luk DC, Tan T, Zhang W, Chiu TW. A validation study of scar vascularity and pigmentation assessment using dermoscopy. Burns : journal of the International Society for Burn Injuries. 2015;41(8):1717-23.

239. Malenfant A, Forget R, Papillon J, Amsel R, Frigon JY, Choiniere M. Prevalence and characteristics of chronic sensory problems in burn patients. Pain. 1996;67(2-3):493-500.

240. Brown JE, Chatterjee N, Younger J, Mackey S. Towards a physiology-based measure of pain: patterns of human brain activity distinguish painful from non-painful thermal stimulation. PLoS One. 2011;6(9):e24124.

241. Meirte J, Moortgat P, Truijen S, Maertens K, Lafaire C, De Cuyper L, et al. Interrater and intrarater reliability of the Semmes Weinstein aesthesiometer to assess touch pressure threshold in burn scars. Burns : journal of the International Society for Burn Injuries. 2015.

242. Tena BB. Evaluación y prevención de la cronificación del dolor postoperatorio tras toracotomía: Universitat de Barcelona. 2014

243. Tena B, Escobar B, Arguis MJ, Cantero C, Rios J, Gomar C. Reproducibility of Electronic Von Frey and Von Frey monofilaments testing. The Clinical journal of pain. 2012;28(4):318-23. 
244. Perry DM, McGrouther DA, Bayat A. Current tools for noninvasive objective assessment of skin scars. Plast Reconstr Surg. 2010;126(3):912-23.

245. Brandt MG, Moore CC, Micomonaco D, Fung K, Franklin JH, Yoo J, et al. A Prospective randomized evaluation of scar assessment measures. Laryngoscope. 2009;119(5):841-5.

246. Niyaz A, Matsumura H, Watanabe K, Hamamoto T, Matsusawa T. Quantification of the physical properties of keloid and hypertrophic scars using the Vesmeter novel sensing device. Int Wound J. 2012;9(6):643-9.

247. Gankande U, Duke J, Wood F, Danielsen PL, Wallace HEVIDENCEBASEDRECOMMENDATIONSFORBURNSCARASSESSMENT. Wound Repair Regen. 2015;23(4):A8-9.

248. Gankande TU, Duke JM, Wood FM, Wallace HJ. Interpretation of the DermaLab Combo((R)) pigmentation and vascularity measurements in burn scar assessment: An exploratory analysis. Burns : journal of the International Society for Burn Injuries. 2015:41(6):1176-85.

249. Singer AJ, Thode Jr HC, McClain SA. Development of a histomorphologic scale to quantify cutaneous scars after burns. Acad Emerg Med. 2000;7(10):1083-8.

250. de Rigal J, Abella ML, Giron F, Caisey L, Lefebvre MA. Development and validation of a new Skin Color Chart. Skin research and technology : official journal of International Society for Bioengineering and the Skin (ISBS) [and] International Society for Digital Imaging of Skin (ISDIS) [and] International Society for Skin Imaging (ISSI). 2007:13(1):101-9.

251. Bloemen MC, van Leeuwen MC, van Vucht NE, van Zuijlen PP, Middelkoop E. Dermal substitution in acute burns and reconstructive surgery: a 12-year follow-up. Plast Reconstr Surg. 2010;125(5):1450-9.

252. Blome-Eberwein SA, Roarabaugh C, Gogal C, Eid S. Exploration of nonsurgical scar modification options: can the irregular surface of matured mesh graft scars be smoothed with microdermabrasion? Journal of burn care \& research : official publication of the American Burn Association. 2012; 33(3):e133-40.

253. Atiyeh BS, Gunn SW, Hayek SN. State of the art in burn treatment. World J Surg. 2005;29(2):131-48.

254. Hoeksema H, Van de Sijpe K, Tondu T, Hamdi M, Van Landuyt K, Blondeel P, et al. Accuracy of early burn depth assessment by laser Doppler imaging on different days post burn. Burns : journal of the International Society for Burn Injuries. 2009;35(1):36-45.

255. Miller RH, Sim I. Physicians' use of electronic medical records: barriers and solutions. Health affairs (Project Hope). 2004;23(2):116-26.

256. Tzou CH, Artner NM, Pona I, Hold A, Placheta E, Kropatsch WG, et al. Comparison of three-dimensional surface-imaging systems. Journal of plastic, reconstructive \& aesthetic surgery : JPRAS. 2014;67(4):489-97.

257. Dobrev H. Application of Cutometer area parameters for the study of human skin fatigue. Skin research and technology : official journal of International Society for Bioengineering and the Skin (ISBS) [and] International Society for Digital Imaging of Skin (ISDIS) [and] International Society for Skin Imaging (ISSI). 2005;11(2):120-2.

\section{Submit your next manuscript to BioMed Central and we will help you at every step:}

- We accept pre-submission inquiries

- Our selector tool helps you to find the most relevant journal

- We provide round the clock customer support

- Convenient online submission

- Thorough peer review

- Inclusion in PubMed and all major indexing services

- Maximum visibility for your research

Submit your manuscript at www.biomedcentral.com/submit

) Biomed Central 